\title{
Clinicopathological and Genomic Analysis of a Chinese ccRCC Patient with Multiple Morphologies and Rapid Progression : A Case Report
}

\section{Jing Yang ( $\sim 172754296 @ q q . c o m)$}

South China University of Technology https://orcid.org/0000-0003-1730-9795

\section{Junyun Wang}

Beijing Institute of Genomics Chinese Academy of Sciences https://orcid.org/0000-0003-0573-7856

Yunshi Liang

Guangzhou First People's Hospital

Jianfei Wang

GloriousMed Clinical Laboratory(Shanghai) Co. Ltd)

Jin Xv

Guangzhou First People's Hospital

Guorong Liu

Guangzhou First People's Hospital

Xiubo Tang

Guangzhou First People's Hospital

Zhaoliang Tang

Guangzhou First People's Hospital

Jinxiang Zhang

Guangzhou First People's Hospital

\section{Yunhai Huang}

Guangzhou First People's Hospital

Hong Yuan

Guangzhou First People's Hospital

\section{Yehui Chen}

Guangzhou First People's Hospital

\section{Case Report}

Keywords: ccRCC, sarcomatoid differentiation, multiple morphologies, molecular features, tumor microenvironment

Posted Date: November 19th, 2020 
DOl: https://doi.org/10.21203/rs.3.rs-108093/v1

License: (c) (1) This work is licensed under a Creative Commons Attribution 4.0 International License. Read Full License 


\section{Abstract}

Background: Renal cell carcinoma (RCC) with sarcomatoid differentiation and multiple metastases is highly aggressive RCC with poor prognosis. However, there are not sufficient report on the genetic alterations and tumor immune microenviroment (TIME) of RCC with complex pathological morphology and aggressive behavior.

Case presentation: A rare Chinese RCC case with complex pathological morphology and multiple subcutaneous and soft tissue metastases was reported. The clinical manifestations, histomorphology, immunophenotype and follow-up data were collected and analyzed. We performed target region sequencing and immunohistochemistry staining in different morphological regions of the primary tumor and the peritoneal metastasis. Microscopically, this primary tumor was composed of three different histological variations, including ccRCC like region, eosinophilic papillary structure and sarcomatoid differentiation. The peritoneal metastasis partially showed rhabdoid differentiation. IHC staining didn't display positivity for characteristic markers. IHC for inflammatory cells showed that CD8+T cells and tumor associated neutrophils (TANs) were significantly increased in the sarcomatous areas and peritoneal metastatic tumor. Genomic analysis indicated that $V H L$ mutations were present in all types of pathological regions and peritoneal metastatic tumor. Therefore, the pathological diagnosis of high-grade CCRCC with sarcomatoid differentiation was established. Additionally, we also found SETD2, TP53 and PDGFRA mutations were observed in sarcomatoid tumor area, whereas BRCA2, ATR, CYLD, YAP1 and COL5A3 mutations were specifically detected in peritoneal metastases. These findings are rather striking because some genes e.g., ATR serine/threonine kinase (ATR) and Hippo signaling (YAP1), PI3K-Akt signaling (PDGFRA) and T cell receptor signaling (COL5A3) were previously reported to be very rare in ccRCC patients.

Conclusions: Using next-generation sequencing and TIME analysis, multiple low-frequency mutant genes including PDGFRA, ATR, YAP1 and COL5A3 and increased CD8+ T cells and neutrophils were detected in this rare Chinese ccRCC. These findings potentially provide new evidence and molecular markers for accurately assessing the biological behavior of ccRCC.

\section{Introduction}

Renal Cell Carcinoma (RCC) is the most common malignant tumor of kidney with an estimated 403,262 new incidences and 175,098 deaths globally in 2018 and the overall incidence rate has been increasing over the past decade $[1,2]$. Clear cell renal cell carcinoma (ccRCC) accounts for $\$ 75 \%$ of kidney cancer diagnoses of RCC [3]..cRCC has long been known to be a highly heterogeneous tumor including morphological heterogeneity and intratumoral genomic heterogeneity. The former is mainly reflected in diverse histological architectural patterns with clear cells or eosinophilic cells [4]. These tumor heterogeneities resulted in variable biological behavior of $\mathrm{CCRCC}$, ranging from low-proliferating localized tumors to highly aggressive metastatic neoplasms. Although the overall survival of ccRCC is good with a 5 -year survival rate of $70 \%$, approximately $25 \%$ of ccRCC patients show distant metastasis at the first 
diagnosis [5]. Thus, accurate assessing the tumor prognosis is important to guide therapeutic intervention and follow-up strategies.

Currently, prognosis evaluation of ccRCC is mainly on the basis of tumor stage and grade. There are also several morphological parameters associated with poor prognosis, such as tumor necrosis, rhabdoid and sarcomatoid differentiation [6]. Studies showed that the 5-year survival rate of the tumor with sarcomatoid differentiation is $15-22 \%$ and the median survival for tumors with rhabdoid morphology is 8-31 months $[7,8]$.

As we known, genetic alterations play a critical role in the tumor initiation, progression and evolution. With the rapid development of gene sequencing technology, researchers discovered that VHL, PBRM1, SETD2 and BAP1 are the most commonly mutated genes of ccRCC [9]. Among these genes, BAP1-mutant tumors are typically high-grade and are associated with poor outcome [10]. Mutation in SETD2 is also associated with poor prognosis of ccRCC [11]. Recently, the research from Samra Turajlic et al. identified genetic diversity and chromosomal complexity as determinants of patient outcome [12]. Moreover, an integrative genomic study of Chinese ccRCCs revealed that the gene mutation landscape in Chinese cohort is different from TCGA dataset, demonstrating significantly higher mutation frequencies in CSMD3 and TMPRSS13 [13]. Therefore, to explore the molecular markers related to ccRCC prognosis in Chinese population is meaningful and important.

In addition, increasing studies indicated that tumor microenvironment (TME) plays an important role in tumor progression, immune escape and drug-resistance [14]. Tumor-associated neutrophils (TANs) and lymphocytes (TILs) are the main components of inflammatory in TME [15]. A study from Song et al. showed that neutrophils are favorably recruited to the RCC cells to promote the RCC migration and invasion [16]. In another study the author developed an architectural pattern-based grading model for cCRCC prognosis evaluation including the intratumoral inflammatory reaction patterns [4].

Herein, we reported a rare Chinese RCC with complicated morphology, extensive metastasis and extremely aggressive behavior. A comprehensive analysis including histopathology, gene alterations and TIME was performed to explore the factors related with aggressive behavior and poor prognosis.

\section{Case Presentation}

The patient was a 56-year-old Chinese man accidentally detected a kidney mass by abdominal ultrasound in outer hospital due to repeated hiccups in August, 2019. Then the patient was referred to our hospital for further diagnosis and treatment in September, 2019. No family tumor history was mentioned and no clinical symptoms were presented, such as flank pain, fever and gross hematuria, nevertheless his weight had lost about 5 kilograms since the onset. Physical examination found that multiple subcutaneous soft nodules located in head, face, neck, waist, abdomen, chest, back and limbs with the diameter from $0.8-1.5 \mathrm{~cm}$, without redness, swelling, ulceration and purulence. The enhanced computed tomography (CT) of abdomen revealed an uneven-density mass in the upper pole of the right kidney and multiple uneven-density nodules in abdominal cavity, abdominal wall, retroperitoneum, pelvic cavity, 
bilateral groin, bilateral psoas muscles, iliopsoas and gluteal muscles, front abdominal wall, back and hip subcutaneous and around the anus (Fig. 1A1, A4 and B4). The kidney mass was measured with the size of $46 \mathrm{~mm} \times 42 \mathrm{~mm} \times 39 \mathrm{~mm}$ and shown low-density and no-enhanced necrotic area in portal phase (Fig. $1 \mathrm{~A} 2$ ). Another low-density nodule was found in the lower pole of the right kidney with the size of $29.74 \times$ $22.70 \times 21.77 \mathrm{~mm}$ (Fig. 1A3). Chest enhanced CT showed no metastasis in the lungs, but there were multiple enlarged stuck nodules in the mediastinum, bilateral armpits and anterior chest wall, which was considered as metastases (Fig. 1B1-B3). A peritoneal metastatic node was removed for frozen-section (yellow triangle) (Fig.1C). Then, a right radical 3D laparoscopic nephrectomy plus peritoneal nodule biopsy was performed. The patient returned to the hospital for review 1 month after surgery and was admitted oral Pazopanib treatment (200mg per tablet, qd) on Oct 13th, 2019. During the treatment of Pazopanib, the patient was getting better physically. Unfortunately, the patient died 1 month later due to excessive medication arbitrarily. The entire course of his clinical treatment is illustrated in Supplementary Fig. 1.

\section{Pathological findings}

\section{Macroscopic findings}

Grossly, the tumor protruding from the renal cortex was confined within the renal parenchyma and measured to be $4.5 \times 4.0 \times 4.0 \mathrm{~cm}$. The cross-section showed a yellowish and spherical neoplasm in the upper pole of the right kidney. The border with the kidney is sharp. Focal hemorrhage and necrosis were identified. In addition, a few dense gray-white nodes were detected in the renal capsule, the perinephric adipose tissue and peritoneum, and their diameter was about 0.3-1.0 cm (Supplementary Fig. 1).

\section{Histopathological and immunohistochemical (IHC) findings}

Microscopic evaluation of the renal tumor showed the tumor was multi-nodular and separated by fibrous tissue. The tumor histology was very complicated with three different histological morphologies, including conventional ccRCC like region, eosinophilic papillary structure and sarcomatoid (spindle) differentiation (Fig. 2A). In ccRCC like region, the pattern of growth was predominantly solid, with formation of nest and acinar patterns separated by the stroma that was characteristically endowed with a prominent network of small, thin-walled blood vessels (Fig. 2Aa1). The area of eosinophilic papillary structure was composed of papillae formed by delicate fibrovascular cores that contain foamy macrophages. Most of these tumor cells showed abundant eosinophilic cytoplasm with occasional small nuclei (Fig. 2Ab1). The sarcomatoid area was lack of distinct borders with the area of clear cells which transition zone between them could be seen. In this region, some little abscesses with lots of neutrophils and tumor necrosis were observed (Fig. 2Ac1). In addition, histopathological examination of the peritoneum node revealed epithelioid sheets of cells exhibiting great pleomorphism and frequent mitoses (Fig. 2B). These tumor cells with eccentric nuclei and abundant eosinophilic cytoplasm resembled rhabdomyoblasts, which was designated as rhabdoid differentiation (Fig. 2B1). 
To identify the specific subtype of this tumor, we completed serious of IHC staining in the primary kidney tumors and peritoneal metastatic node. These immunostainings showed that CK8/18 and EMA were diffuse or patchy strong positivity in the classical ccRCC like area and eosinophilic papillary area (Fig. 2Aa2-3, 2Ab2-3), while their expressions were reduced in the sarcomatoid area and peritoneal metastatic node (Fig. 2Ac2-3, 2B2-3). To the opposite, vimentin was expressed more intensely and diffusely in the

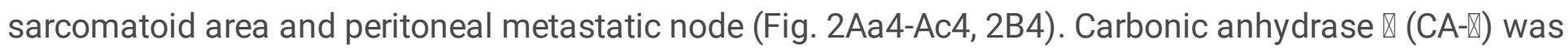
present strongly and diffusely in the intact membranous distribution in the clear cells and those tumor cells in the eosinophilic papillary area, which was negative in sarcomatoid cells (Fig. 2Aa5-Ac5, 2B5). Tumor cells in these four lesions were negative for CD10, CK7, CD117, PAX8, MelanA, HMB45, SMA, Myogenin, Syn, $\mathrm{CgA}$ and ALK and retained SMARCB1 (INI-1) expression. The immunostaining summary information could be seen in Supplementary Table 1.

\section{Tumor immune microenvironment (TIME) analysis of different regions}

Due to numerous inflammatory cells accumulating in the sarcomatoid area and peritoneal metastatic node, we further detected the status of the immune tumor microenvironment via the IHC staining of LCA, CD8, CD4 and MPO and evaluated inflammatory cells in the cCRCC like region, sarcomatoid area and peritoneal metastatic tumor, respectively. We found that lymphocytes were mostly distributed in the border of different morphological tumor node, but not in the center of lesion, while the distribution of neutrophils had no zonal (Fig. 3A). The number of TILs infiltrating on the border of sarcomatoid area was significantly more than the $c c R C C$ like region ( $p=0.0144$, Fig. 3Aa2-b2 and 3C). Amount of CD8+ T cells in the sarcomatous area and peritoneal metastasis tumor were significantly more than CCRCC

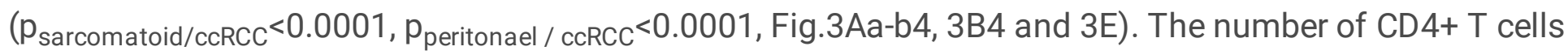
in the peritonaeul tumor was slightly higher than $\mathrm{CCRCC}$ area and sarcomatous area $\left(\mathrm{p}_{\text {peritonael/ccRCC }}\right.$ $=0.0161, p_{\text {peritonael } / \text { sarcomatoid }}=0.0161$, Fig.3Aa3-b3, 3B3 and 3D). It implies that CD $8+T$ cells preferred infiltrating into the high grade RCC compared with CD4+ T cells. Moreover, neutrophils were more enriched in the sarcomatous areas and peritoneal tumor than ccRCC like region $\left(p_{\text {sarcomatoid/ccRCc }}<0.0001, p_{\text {sarcomatoid/peritonae }}<0.0001\right.$, Fig. 3Aa5-b5, 3B5 and 3F).

\section{Gene mutation analysis with target capture sequencing}

To confirm the accurate subtype of tumor and further reveal the underlying molecular mechanism related heterogeneous morphology and extremely aggressive biological behavior, genomic profiling of the four distinct morphology tissue slides from resected tumor specimens was achieved by using target capture sequencing with a designed panel of 620 key cancer-related genes (GloriousMed Clinical Laboratory Co., Shanghai, China). The distribution of somatic mutations (SNV, InDel) among four different morphological tissues from this patient are summarized in a Venn diagram (Fig. 4A).

The most common $V H L$ mutations in ccRCC were detected in all of them, including primary and peritoneal metastatic foci (Fig. 4B). Therefore, we identified this patient as a high-grade clear cell renal cell carcinoma (ccRCC) with with sarcomatoid differentiation and systemic multiple metastases 
(pT3aN1M1). Further analysis indicated tumor of eosinophilic papillary area carries the fewest number and types of mutated genes among all tumor tissues, only $V H L$ and $B A P 1$ mutation, suggesting that these two genes might be early events in ccRCC tumorigenesis. From the perspective of genomic changes, eosinophilic morphology tumor seems to occur in the earliest stage of the disease due to the minimum number of driver gene alterations and mutation types. Notably, histone modification gene SETD2 mutations were detected in all of tumor regions except for eosinophilic papillary area, suggesting SETD2 could play an important role in ccRCC progression.

Remarkably, the genetic alterations in sarcomatoid regions are similar to those in clear cell carcinoma areas, both sharing some identical gene mutations such as VHL(p. R64fs), SETD2(p.N1628T), SMAD4(p.Q534fs*3), and PTPRT(p.A696V). BAP1 variant P190R and ATM variant E1199 deletion were observed only in conventional clear cell carcinomas, whereas there were exclusive TP53 variant A347G and PDGFRA variant S890 frameshift deletion in sarcomatoid-like tumor, hinting that TP53 and PDGFRA may play a significant role in the sarcomatoid transformation from ccRCC morphology. BRCA2 and ATR involved in DNA damage response pathway, NF-kappa B signaling gene CYLD and Hippo signaling gene $Y A P 1$, protein digestion and absorption gene $C O L 5 A 3$ were specifically detected in peritoneal metastatic node but not in other primary areas (Fig. 4B).

Besides, the tumor mutation burden (TMB) value of the four tumor areas present some certain regularities. The higher the grade, the higher the TMB value, as expected, the worse the prognosis, especially with sarcomatoid lesions. The TMB of peritoneal metastatic tumor was higher than the primary tumor (Fig. 4C). The TMB evidence also supports that tumor of eosinophilic papillary area and ccRCC area occurred at the early stage, then the tumor developed into the sarcomatoid morphology, and lastly metastasized to multiple organs including the peritoneum.

The last main thing is that this patient harbored several somatic mutations of certain genes including histone methyltransferase SETD2 (SET domain containing 2), ATR serine/threonine kinase (ATR), ATM serine/threonine kinase (ATM) and TP53 associated with DNA damage response signaling and Hippo signaling (YAP1), PI3K-Akt signaling (PDGFRA) and T cell receptor signaling (COL5A3) (Fig. 4B), some of which contribute to the development of the RCC in light of previous data $[9,17,18]$.

\section{Discussion}

This is a really complex, difficult and rare RCC case even though it was identified high-grade advanced cCRCC with sarcomatoid differentiation by gene sequencing finally. But making an accurate pathological diagnosis for this case is very difficult in the beginning because it presented complicated pathological morphology as mentioned before and lacked the expression of characteristic immune markers. For example, a classical ccRCC marker CD10 was negative in all of tumor areas. Meanwhile, we excluded chromophobe renal cell carcinoma (ChRCC), MiT family translocation carcinoma, renal medullary carcinoma and ALK rearrangement-associated RCC because of the lack of CK7, CD117, MelanA, HMB45, TFE3 and ALK expression and retaining SMARCB1 (INI-1) expression. Additionally, we also excluded clear 


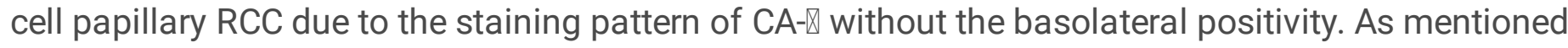
above, this tumor was highly invasive and metastasis had occurred in the multiple parts of the body including subcutaneous, soft tissue, lymph nodes and so on at the beginning of diagnosis. Sarcomatoid differentiation in the primary tumor was undoubtedly one of the important reasons of its high aggressiveness. Published data showed that this feature is found in $5-8 \%$ of ccRCC, $8-9 \%$ of ChRCC, and $2-3 \%$ of PRCC [19-22]. Additionally, in the context of the current 2016 WHO classification system, tumors in the unclassified RCC ( $\mathrm{URCC}$ ) category can be those with a combination of features of more than one recognized subtype, with mucin production or with unrecognized epithelial cell subtypes, low- or high-grade unclassified oncocytic neoplasms, and other unclassifiable renal tumors [23]. Sarcomatoid differentiation is also included in the morphology spectrum of URCC. Some research data from a few relatively large series of URCC suggest a comparably poor or worse outcome than high-stage ccRCC [24]. Hence, it is critical to determine the tumor subtype and explore the underlying molecular mechanism of highly aggressive biological behavior via target gene sequencing in four different tumor areas including metastatic foci

In this study, we detected $V H L$ mutations in all of tumor areas including the primary tumor with three different morphologies and metastasis. It confirmed that this tumor was cCRCC and its different components are originated from the same progenitor cell.

Because of huge tumor heterogeneity, the mutation profiles between in situ foci and metastases are varied, especially for driver mutations. BRCA2 and ATR involved in DNA damage response pathway, NFkappa B signaling gene $C Y L D$ and Hippo-YAP signaling gene $Y A P 1$, protein digestion and absorption gene COL5A3 was specifically detected in peritoneal metastatic node but not in other primary areas, indicating that these gene mutations might play an important role in promoting tumor metastasis. Importantly, the alterations (especially deleterious gene mutations) of DDR genes exhibited potential value of predicting response to immune checkpoint inhibitors for metastatic RCC patients [25]. Given the key role of these signaling pathways in the feature of DNA repair, cell proliferation and metastasis, these mutations might contribute to this patient's rapid progression and high aggressiveness.

It was reported that patients with sarcomatoid carcinoma have a poorer prognosis than classical ccRCC $[8,26]$, therefore uncovering the genomic characterization of sarcomatoid transformation in ccRCC is vital. The most altered pathways of sarcomatoid RCC (sRCC) involved VHL (72\%), chromatin remodeling genes (72\%), MTOR pathway (50\%), DNA repair (30\%), and the Hippo-YAP pathway (20\%) [27]. The research from Wang $Z$ and colleagues indicated more mutations in TP53, PTEN and RELN occurred in sRCC compared with cCRCC [28]. In addition, tyrosine kinase PDGFR-a (PDGFRA) gain of function mutations play a crucial role in RCC pathogenesis. Higher expression of tyrosine kinase receptor PDGFRa was observed in the sRCC part (81.2\%) in comparison with the epithelial part (43.7\%) and more common mutation of PDGFRA in a subset SRCC cases where sarcomatoid differentiation showed overexpression of this proteins [29]. In this study, SETD2 variant N1628T, TP53 variant A347G and PDGFRA variant S890 frameshift deletion were detected in sarcomatoid-like tumor, which may be the intrinsic cause of sarcoma tumor progression and suggested that patient can benefit from the imatinib drug. This example among 
others provides a model of how oncogenic activation of tyrosine kinase maintains the highly aggressive clinicopathological features and poor prognosis.

The tumor microenvironment consisting of several cellular and extracellular matrix components is closely related to the outcome of tumor progression by promoting tumor growth, tumor invasion as well as metastatic growth [30]. In immune cell TME compartments of RCC, studies indicated that subdivided macrophages and T cells are the main immune cells [31, 32]. In July 2018 Wang et al. described a new RCC subtype, namely the inflamed pan-RCC subtype (IS) and revealed that IS RCCs are enriched for Tregs, NK cells, neutrophils, macrophages, B-cells, TH1 cells, and CD $8+T$ cells and are importantly associated with poor prognosis and poor survival [33]. Some papers also reported that the immune microenvironment of RCC is unique compared with other solid tumors [2]. Resected RCC tumors are usually wide-spread infiltrated by CD8 $+T$ cells and an increased level of infiltrating CD8 $+T$ cells is associated with worse outcome in RCC [34], while in the other solid tumors infiltrating CD8 + T cells are associated with a better prognosis[35]. In our study, CD8 + T cells and tumor associated neutrophils (TANs) significantly increased in the more aggressive tumor components (sarcomatous area and peritoneal metastasis tumor) compared with ccRCC. It explained the highly aggressive biological behavior from the modification of tumor microenvironment (TME) and suggested that the patient may benefit from immunotherapy due to extensive infiltrated of $\mathrm{CD} 8+\mathrm{T}$ cells and neutrophils. Further data are needed to determine whether CD $8+T$ cell density might be a biomarker for immunotherapy.

This study has several limitations, including its small sample size, lack of transcriptome analysis due to insufficient quality of RNA and non-coding gene analysis. Despite the limitations, based on molecular features and TIME analysis, we have identified a rare Chinese case of CCRCC with sarcomatoid differentiation, extensive tumor metastasis and poor prognosis. Furthermore, multiple low-frequency mutant genes including PDGFRA, ATR, YAP-1 and COL5A3, activated tumor infiltrating CD $8+$ cells and increased neutrophils were detected in this study, which provided genetic explanation of the highly heterogeneous nature of ccRCC and poor prognosis. These findings provide new evidence and potential for accurately assessing the biological behavior of ccRCC.

\section{Conclusions}

Using next-generation sequencing and TIME analysis, multiple low-frequency mutant genes including PDGFRA, ATR, YAP1 and COL5A3, activated infiltrating CD8 + T cells and increased neutrophils were detected in a rare Chinese ccRCC with sarcomatoid differentiation and extremely aggressive biological behavior. These findings potentially provide new evidence and molecular markers for accurately assessing the biological behavior of ccRCC.

\section{Abbreviations}

RCC

renal cell carcinoma; 
cCRCC

clear cell renal cell carcinoma;

sRCC

sarcomatoid renal cell carcinoma;

TIME

tumor immune microenvironment;

TME

tumor microenvironment;

TANs

tumor associated neutrophils;

TMB

tumor mutation burden;

SETD2

SET domain containing 2;

ATR

ataxia telangiectasia and Rad3 related;

ATM

Ataxia-telangiectasia mutated;

IHC

immunohistochemistry

\section{Declarations}

\section{Acknowledgment}

This work was supported by the National Natural Science Foundation of China (grant no. 81702796)

\section{Authors' contributions}

Jing Yang and Junyun Wang conceived the study. Yehui Chen is the corresponding author. Jing Yang obtained samples and performed the pathology review. Yunshi Liang, Jin Xv and Zhaoliang Tang completed pathological diagnosis, data collection and analysis. Jinxiang Zhang and Hong Yuan collected clinic history data and followed up. Guorong Liu and Xiubo Li performed IHC staining. Yunhai Huang evaluated the results of the computed tomography (CT). Junyun Wang performed the bioinformatic analysis. Jing Yang, Junyun Wang and Jianfei Wang analyzed and interpreted the data. JingYang and Junyun Wang wrote the first manuscript, which was reviewed by all coauthors.

\section{Funding}

The authors have no funding to disclose 
Availability of data and materials

The datasets used and/or analyzed during the current study are available from the corresponding author on reasonable request

\section{Ethics approval and consent to participate}

The present study was approved by the ethics committee of Guangzhou First People's Hospital and adhered to the tenets of the Declaration of Helsinki.

\section{Consent for publication}

Patient signed an informed consent for publication of the case report.

\section{Competing interests}

The authors declare that they have no competing interests.

\section{References}

1. Znaor A, Lortet-Tieulent J, Laversanne M, Jemal A, Bray F. International variations and trends in renal cell carcinoma incidence and mortality. Eur Urol. 2015;67(3):519-30.

2. Xu W, Atkins MB, McDermott DF. Checkpoint inhibitor immunotherapy in kidney cancer. Nat Rev Urol. 2020;17(3):137-50.

3. Rini BCS, Escudier B. Renal cell carcinoma. Lancet. 2009;373(9669):1119-32.

4. Verine J, Colin D, Nheb M, Prapotnich D, Ploussard G, Cathelineau X, et al. Architectural Patterns are a Relevant Morphologic Grading System for Clear Cell Renal Cell Carcinoma Prognosis Assessment: Comparisons With WHO/ISUP Grade and Integrated Staging Systems. Am J Surg Pathol. 2018;42(4):423-41.

5. Abdou AG, Kandil M, Elshakhs S, El-Dien MS, Abdallah R. Renal cell carcinoma with rhabdoid and sarcomatoid features presented as a metastatic thigh mass with an unusual immunohistochemical profile. Rare Tumors. 2014;6(1):5037.

6. Yang C, Shuch B, Serrano M, Kibel AS, Nawaf C, Vollmer R, et al. Adverse Histopathologic Characteristics in Small Clear Cell Renal Cell Carcinomas Have Negative Impact on Prognosis: A Study of 631 Cases With Clinical Follow-up. Am J Surg Pathol. 2019;43(10):1413-20.

7. Zhang BY, Cheville JC, Thompson RH, Lohse CM, Boorjian SA, Leibovich BC, et al. Impact of Rhabdoid Differentiation on Prognosis for Patients with Grade 4 Renal Cell Carcinoma. Eur Urol. 2015;68(1):5-7.

8. Pichler R, Comperat E, Klatte T, Pichler M, Loidl W, Lusuardi L, et al. Renal Cell Carcinoma with Sarcomatoid Features: Finally New Therapeutic Hope? Cancers (Basel). 2019; 11(3).

9. Cancer Genome Atlas Research N. Comprehensive molecular characterization of clear cell renal cell carcinoma. Nature. 2013;499(7456):43-9. 
10. Wi YC, Moon A, Jung MJ, Kim Y, Bang SS, Jang K, et al. Loss of Nuclear BAP1 Expression Is Associated with High WHO/ISUP Grade in Clear Cell Renal Cell Carcinoma. J Pathol Transl Med. 2018;52(6):378-85.

11. Hakimi AA, Ostrovnaya I, Reva B, Schultz N, Chen YB, Gonen M, et al. Adverse outcomes in clear cell renal cell carcinoma with mutations of 3p21 epigenetic regulators BAP1 and SETD2: a report by MSKCC and the KIRC TCGA research network. Clin Cancer Res. 2013;19(12):3259-67.

12. Mitchell TJ, Turajlic S, Rowan A, Nicol D, Farmery JHR, O'Brien T, et al. Timing the Landmark Events in the Evolution of Clear Cell Renal Cell Cancer: TRACERx Renal. Cell. 2018;173(3):611-23 e617.

13. Wang XM, Lu Y, Song YM, Dong J, Li RY, Wang GL, et al. Integrative genomic study of Chinese clear cell renal cell carcinoma reveals features associated with thrombus. Nat Commun. 2020;11(1):739.

14. Gul A, Rini BI. Adjuvant therapy in renal cell carcinoma. Cancer. 2019;125(17):2935-44.

15. Liu K, Zhao K, Wang L, Sun E. The prognostic values of tumor-infiltrating neutrophils, lymphocytes and neutrophil/lymphocyte rates in bladder urothelial cancer. Pathol Res Pract. 2018;214(8):107480.

16. Song W, Yeh CR, He D, Wang Y, Xie H, Pang ST, et al. Infiltrating neutrophils promote renal cell carcinoma progression via VEGFa/HIF2alpha and estrogen receptor beta signals. Oncotarget. 2015;6(22):19290-304.

17. Miao D, Margolis CA, Gao W, Voss MH, Li W, Martini DJ, et al. Genomic correlates of response to immune checkpoint therapies in clear cell renal cell carcinoma. Science. 2018;359(6377):801-6.

18. Testa U, Pelosi E, Castelli G. Genetic Alterations in Renal Cancers: Identification of The Mechanisms Underlying Cancer Initiation and Progression and of Therapeutic Targets. Medicines (Basel). 2020; 7(8).

19. Jones TD, Eble JN, Wang M, Maclennan GT, Jain S, Cheng L. Clonal divergence and genetic heterogeneity in clear cell renal cell carcinomas with sarcomatoid transformation. Cancer. 2005;104(6):1195-203.

20. Cheville JC, Lohse CM, Zincke H, Weaver AL, Leibovich BC, Frank I, et al. Sarcomatoid renal cell carcinoma: an examination of underlying histologic subtype and an analysis of associations with patient outcome. Am J Surg Pathol. 2004;28(4):435-41.

21. de Peralta-Venturina M, Moch H, Amin M, Tamboli P, Hailemariam S, Mihatsch M, et al. Sarcomatoid differentiation in renal cell carcinoma: a study of 101 cases. Am J Surg Pathol. 2001;25(3):275-84.

22. Amin MB, Paner GP, Alvarado-Cabrero I, Young AN, Stricker HJ, Lyles RH, et al. Chromophobe renal cell carcinoma: histomorphologic characteristics and evaluation of conventional pathologic prognostic parameters in 145 cases. Am J Surg Pathol. 2008;32(12):1822-34.

23. Moch H, Cubilla AL, Humphrey PA, Reuter VE, Ulbright TM. The 2016 WHO Classification of Tumours of the Urinary System and Male Genital Organs-Part A: Renal, Penile, and Testicular Tumours. Eur Urol. 2016;70(1):93-105.

24. Crispen PL, Tabidian MR, Allmer C, Lohse CM, Breau RH, Blute ML, et al. Unclassified renal cell carcinoma: impact on survival following nephrectomy. Urology. 2010;76(3):580-6. 
25. Ged Y, Chaim JL, DiNatale RG, Knezevic A, Kotecha RR, Carlo MI, et al. DNA damage repair pathway alterations in metastatic clear cell renal cell carcinoma and implications on systemic therapy. $\mathrm{J}$ Immunother Cancer. 2020; 8(1).

26. Zhao Y, Chen H, Xie Y, Zhang C, Hou Y, Jin M. Clinicopathologic features and prognostic factors in patients with renal cell carcinoma with sarcomatoid differentiation. APMIS. 2020;128(5):378-86.

27. Malouf GG, Flippot R, Dong Y, Dinatale RG, Chen YB, Su X, et al. Molecular characterization of sarcomatoid clear cell renal cell carcinoma unveils new candidate oncogenic drivers. Sci Rep. 2020;10(1):701.

28. Wang Z, Kim TB, Peng B, Karam J, Creighton C, Joon A, et al. Sarcomatoid Renal Cell Carcinoma Has a Distinct Molecular Pathogenesis, Driver Mutation Profile, and Transcriptional Landscape. Clin Cancer Res. 2017;23(21):6686-96.

29. Petit A, Castillo M, Gaspa A, Colomer D, Garcia de Albeniz X, Moreno C, et al. Expression and mutational analyses of KIT and PDGFR-alpha in sarcomatoid renal cell carcinoma. Histopathology. 2009;55(2):230-2.

30. Wang M, Zhao J, Zhang L, Wei F, Lian Y, Wu Y, et al. Role of tumor microenvironment in tumorigenesis. J Cancer. 2017;8(5):761-73.

31. Chevrier S, Levine JH, Zanotelli VRT, Silina K, Schulz D, Bacac M, et al. An Immune Atlas of Clear Cell Renal Cell Carcinoma. Cell. 2017;169(4):736-49 e718.

32. Ricketts CJ, De Cubas AA, Fan H, Smith CC, Lang M, Reznik E, et al. The Cancer Genome Atlas Comprehensive Molecular Characterization of Renal Cell Carcinoma. Cell Rep. 2018;23(1):313-26 e315.

33. Wang T, Lu R, Kapur P, Jaiswal BS, Hannan R, Zhang Z, et al. An Empirical Approach Leveraging Tumorgrafts to Dissect the Tumor Microenvironment in Renal Cell Carcinoma Identifies Missing Link to Prognostic Inflammatory Factors. Cancer Discov. 2018;8(9):1142-55.

34. Giraldo NA, Becht E, Pages F, Skliris G, Verkarre V, Vano Y, et al. Orchestration and Prognostic Significance of Immune Checkpoints in the Microenvironment of Primary and Metastatic Renal Cell Cancer. Clin Cancer Res. 2015;21(13):3031-40.

35. Fridman WH, Pages F, Sautes-Fridman C, Galon J. The immune contexture in human tumours: impact on clinical outcome. Nat Rev Cancer. 2012;12(4):298-306.

\section{Figures}



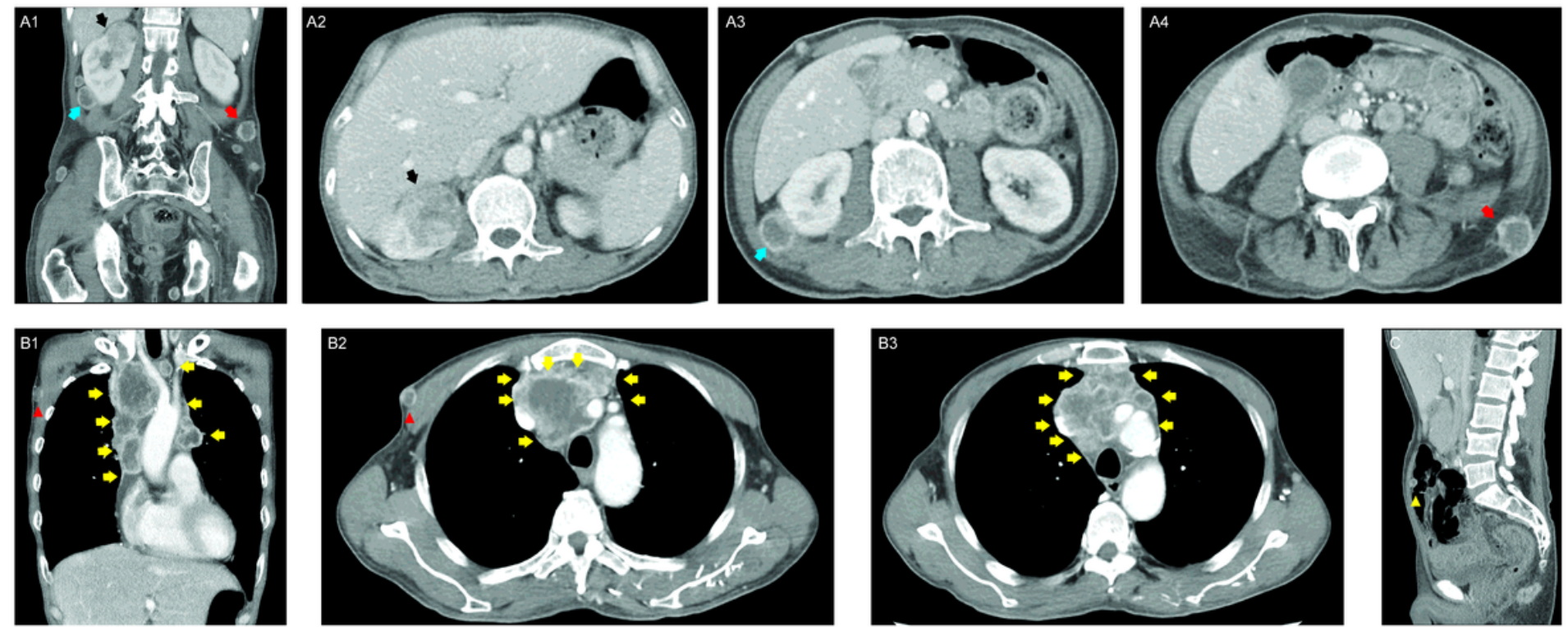

Figure 1

The entire course of his clinical treatment is illustrated and contrast-enhanced computed tomography in portal phase of the thoraco-abdomen. (A1-A4) Abdomen enhanced CT showed an uneven-density mass (black arrow) in the upper pole of the right kidney and multiple uneven-density nodules abdominal cavity, abdominal wall, retroperitoneum, pelvic cavity, bilateral groin, bilateral psoas muscles, iliopsoas and gluteal muscles, front abdominal wall, back and hip subcutaneous (red arrow) and around the anus. (A3) Another low-density nodule was found in the lower pole of the right kidney (blue arrow). (B1-B3) Chest enhanced CT showed multiple enlarged stuck nodules formed a huge irregular mass (yellow arrow) in the mediastinum and a metastatic nodule was in the anterior chest wall (red triangle). (C) A peritoneal metastatic node was removed for frozen-section (yellow triangle).
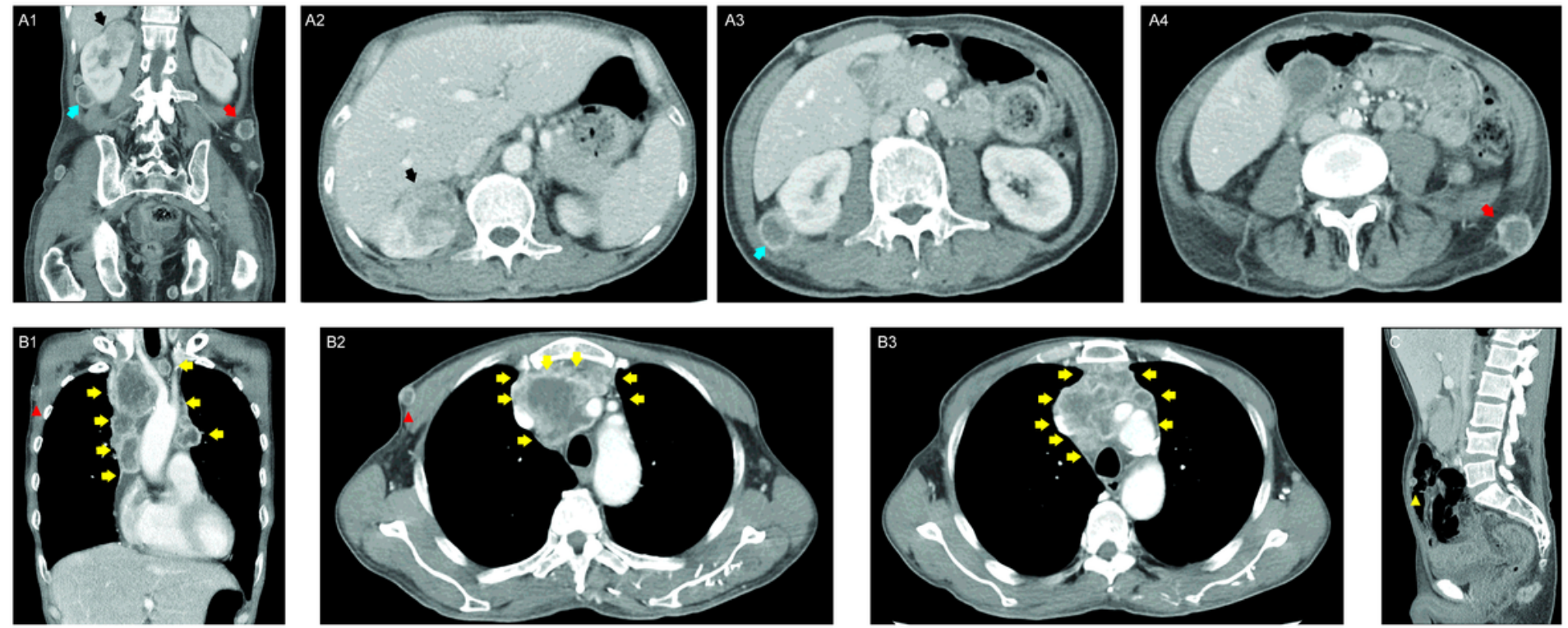

Figure 1 
The entire course of his clinical treatment is illustrated and contrast-enhanced computed tomography in portal phase of the thoraco-abdomen. (A1-A4) Abdomen enhanced CT showed an uneven-density mass (black arrow) in the upper pole of the right kidney and multiple uneven-density nodules abdominal cavity, abdominal wall, retroperitoneum, pelvic cavity, bilateral groin, bilateral psoas muscles, iliopsoas and gluteal muscles, front abdominal wall, back and hip subcutaneous (red arrow) and around the anus. (A3) Another low-density nodule was found in the lower pole of the right kidney (blue arrow). (B1-B3) Chest enhanced CT showed multiple enlarged stuck nodules formed a huge irregular mass (yellow arrow) in the mediastinum and a metastatic nodule was in the anterior chest wall (red triangle). (C) A peritoneal metastatic node was removed for frozen-section (yellow triangle).
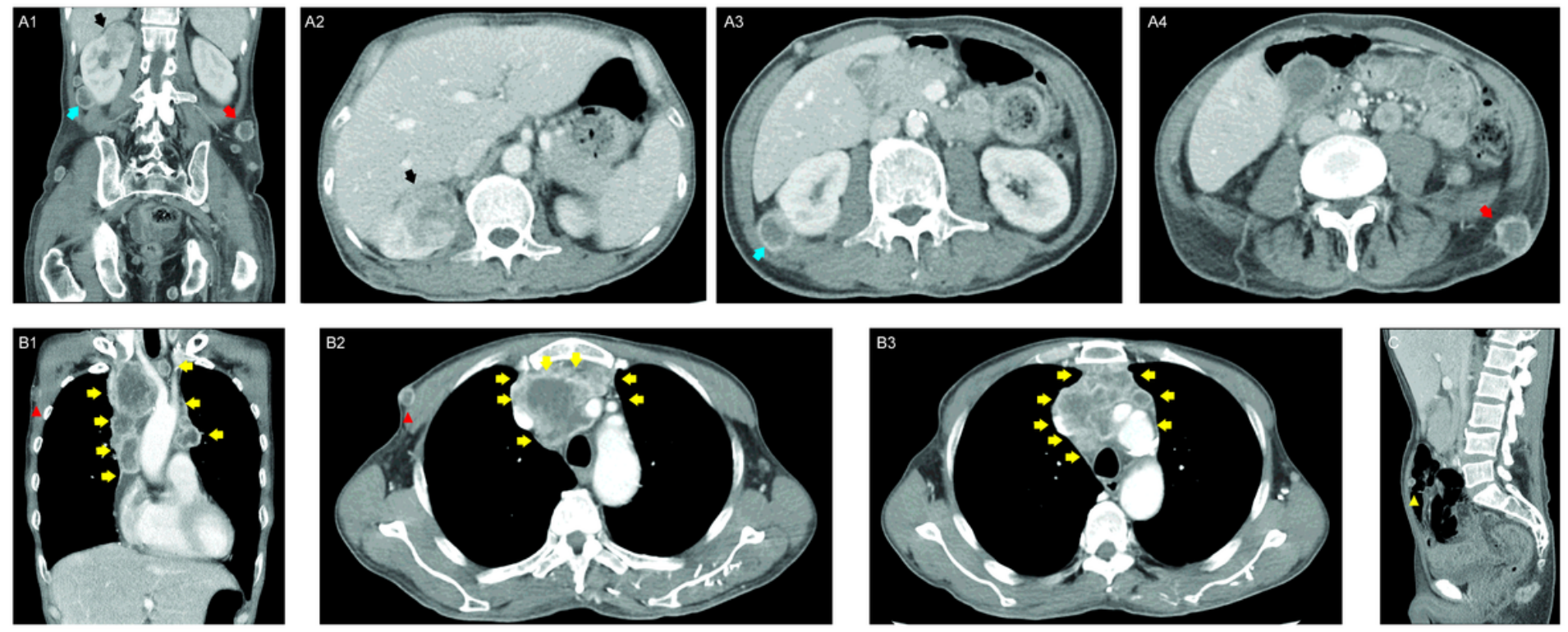

Figure 1

The entire course of his clinical treatment is illustrated and contrast-enhanced computed tomography in portal phase of the thoraco-abdomen. (A1-A4) Abdomen enhanced CT showed an uneven-density mass (black arrow) in the upper pole of the right kidney and multiple uneven-density nodules abdominal cavity, abdominal wall, retroperitoneum, pelvic cavity, bilateral groin, bilateral psoas muscles, iliopsoas and gluteal muscles, front abdominal wall, back and hip subcutaneous (red arrow) and around the anus. (A3) Another low-density nodule was found in the lower pole of the right kidney (blue arrow). (B1-B3) Chest enhanced CT showed multiple enlarged stuck nodules formed a huge irregular mass (yellow arrow) in the mediastinum and a metastatic nodule was in the anterior chest wall (red triangle). (C) A peritoneal metastatic node was removed for frozen-section (yellow triangle). 

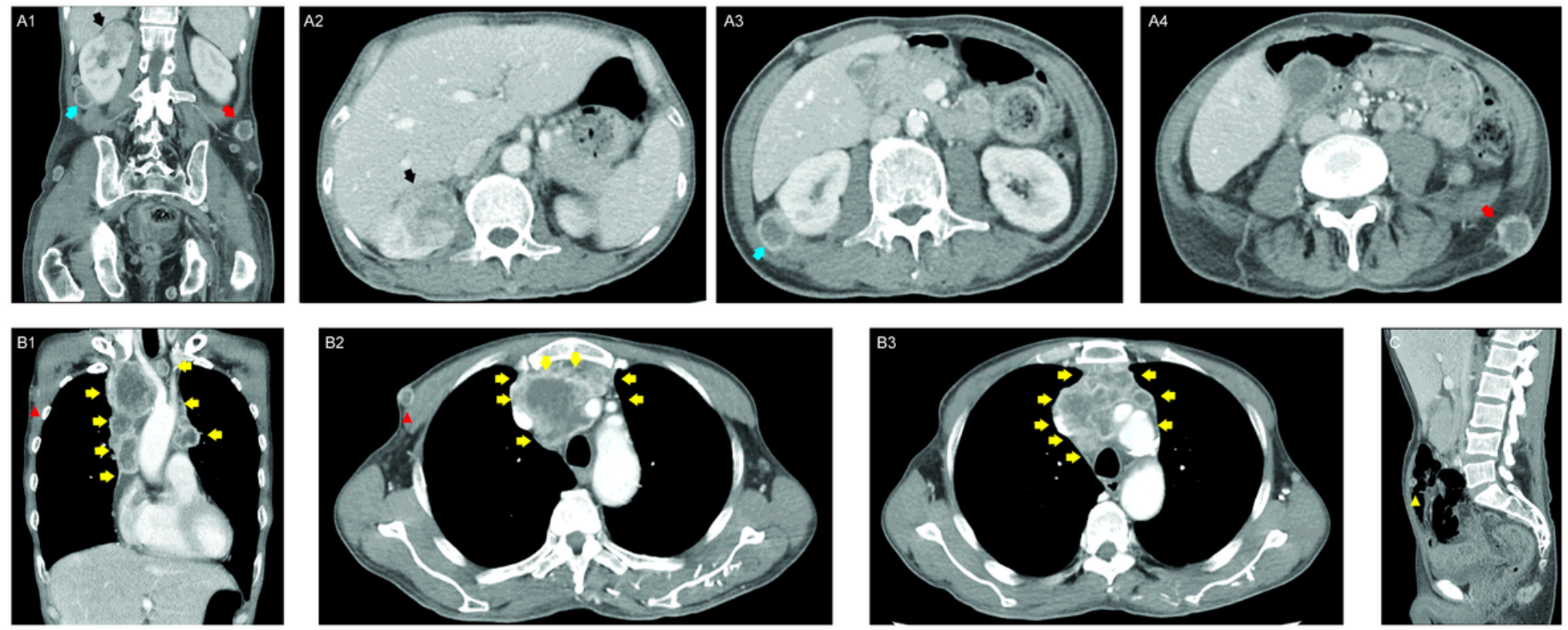

\section{Figure 1}

The entire course of his clinical treatment is illustrated and contrast-enhanced computed tomography in portal phase of the thoraco-abdomen. (A1-A4) Abdomen enhanced CT showed an uneven-density mass (black arrow) in the upper pole of the right kidney and multiple uneven-density nodules abdominal cavity, abdominal wall, retroperitoneum, pelvic cavity, bilateral groin, bilateral psoas muscles, iliopsoas and gluteal muscles, front abdominal wall, back and hip subcutaneous (red arrow) and around the anus. (A3) Another low-density nodule was found in the lower pole of the right kidney (blue arrow). (B1-B3) Chest enhanced CT showed multiple enlarged stuck nodules formed a huge irregular mass (yellow arrow) in the mediastinum and a metastatic nodule was in the anterior chest wall (red triangle). (C) A peritoneal metastatic node was removed for frozen-section (yellow triangle). 

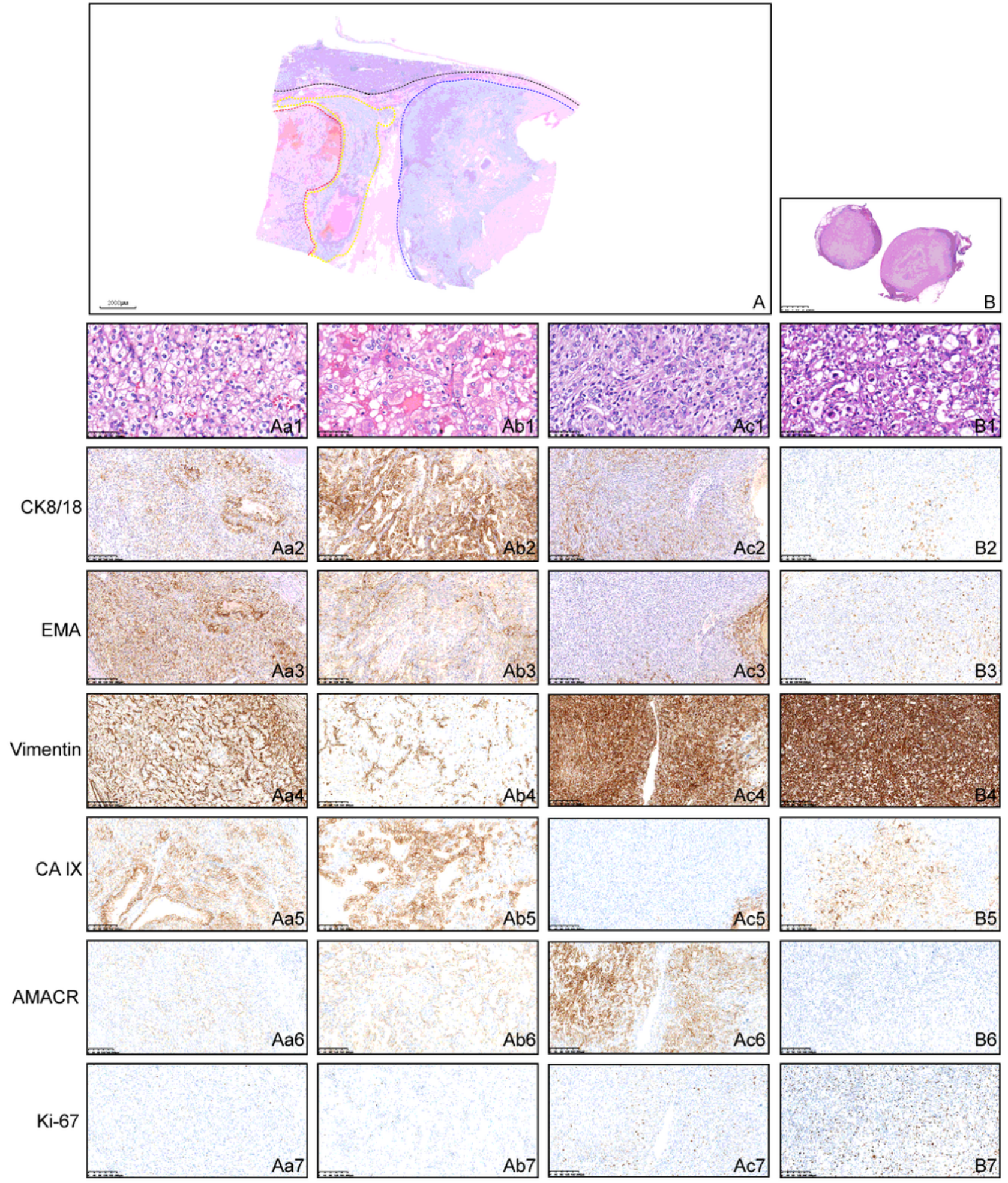

\section{Figure 2}

Pathological morphologies and immunohistochemistry staining of renal cell carcinoma and peritoneal tumoral node. (A)Low magnification of the renal cell carcinoma. Scale bar $=2000 \mathrm{~mm}$. Yellow line exhibited the clear-cell carcinoma; Red line exhibited the eosinophilic papillary area; Blue line exhibited the sarcomatous change area; Black line exhibited the normal renal tissue. (Aa1) RCC with the morphology of classical ccRCC. Scale bar=50mm;(Aa2-a7) Immunostaining for CK8/18, EMA, Vimentin, CAIX, AMACR 
and Ki67 in classical ccRCC area. (Ab1) RCC with eosinophilic papillary structure, Scale bar=50mm. (Ab2b7) Immunostaining for CK8/18, EMA, vimentin, CAIX, AMACR and Ki67 in papillary area (Ac1) RCC with sarcomatoid (spindle) cells and clear nucleolus. Scale bar=50mm. (Ac2-7) Immunostaining for CK8/18, EMA, Vimentin, CAIX, AMACR and Ki67 in sarcomatous area, Scale bar=50mm. (B)Low magnification of the peritoneal tumoral node. Scale bar $=2000 \mathrm{~mm}$. (B1) Peritoneal tumor with spindle cells and rhabdoid cells. Scale bar=50mm. (B2-7) Immunostaining for CK8/18, EMA, Vimentin, CAIX, AMACR and Ki67 in peritoneal tumoral node.
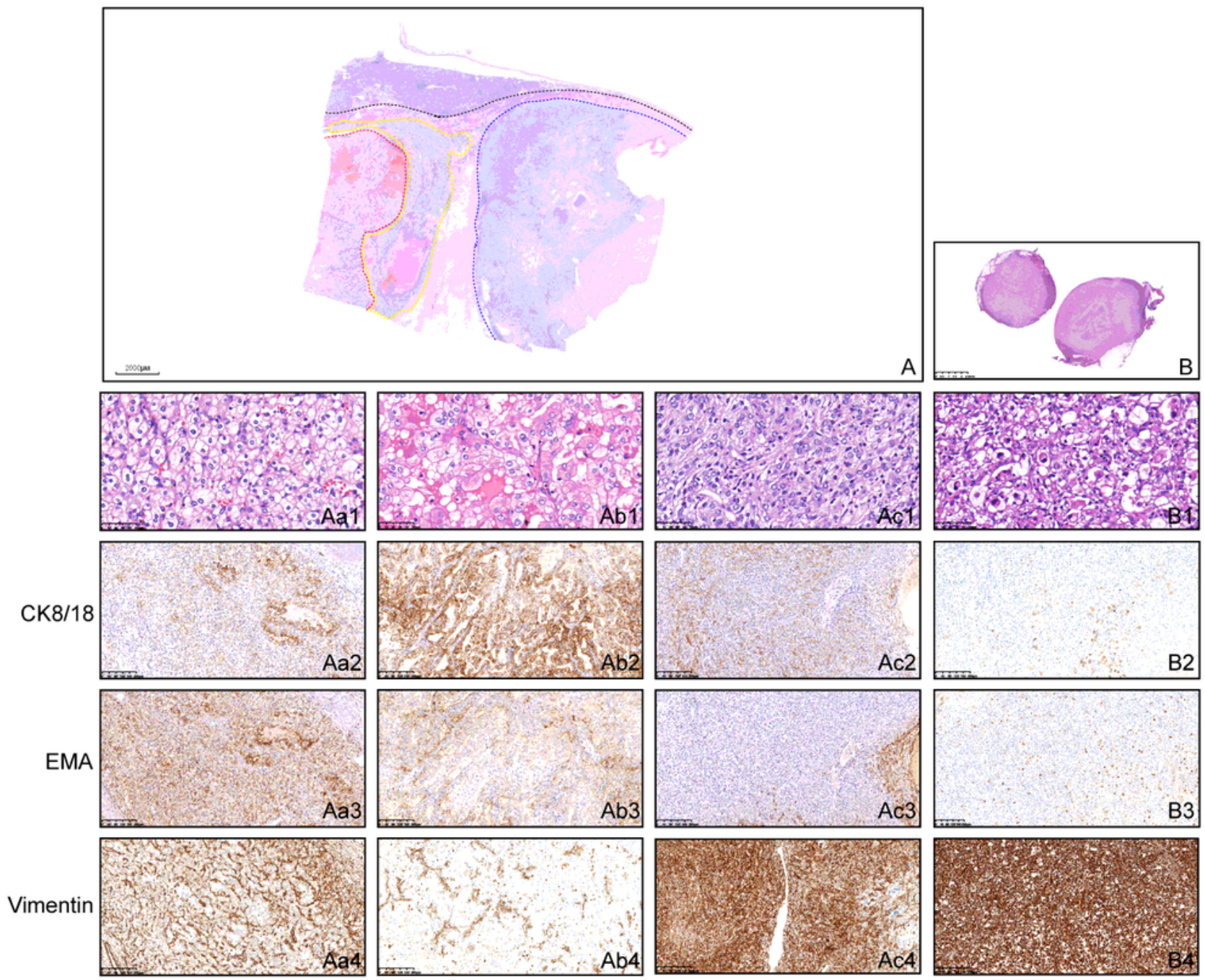

Vimentin
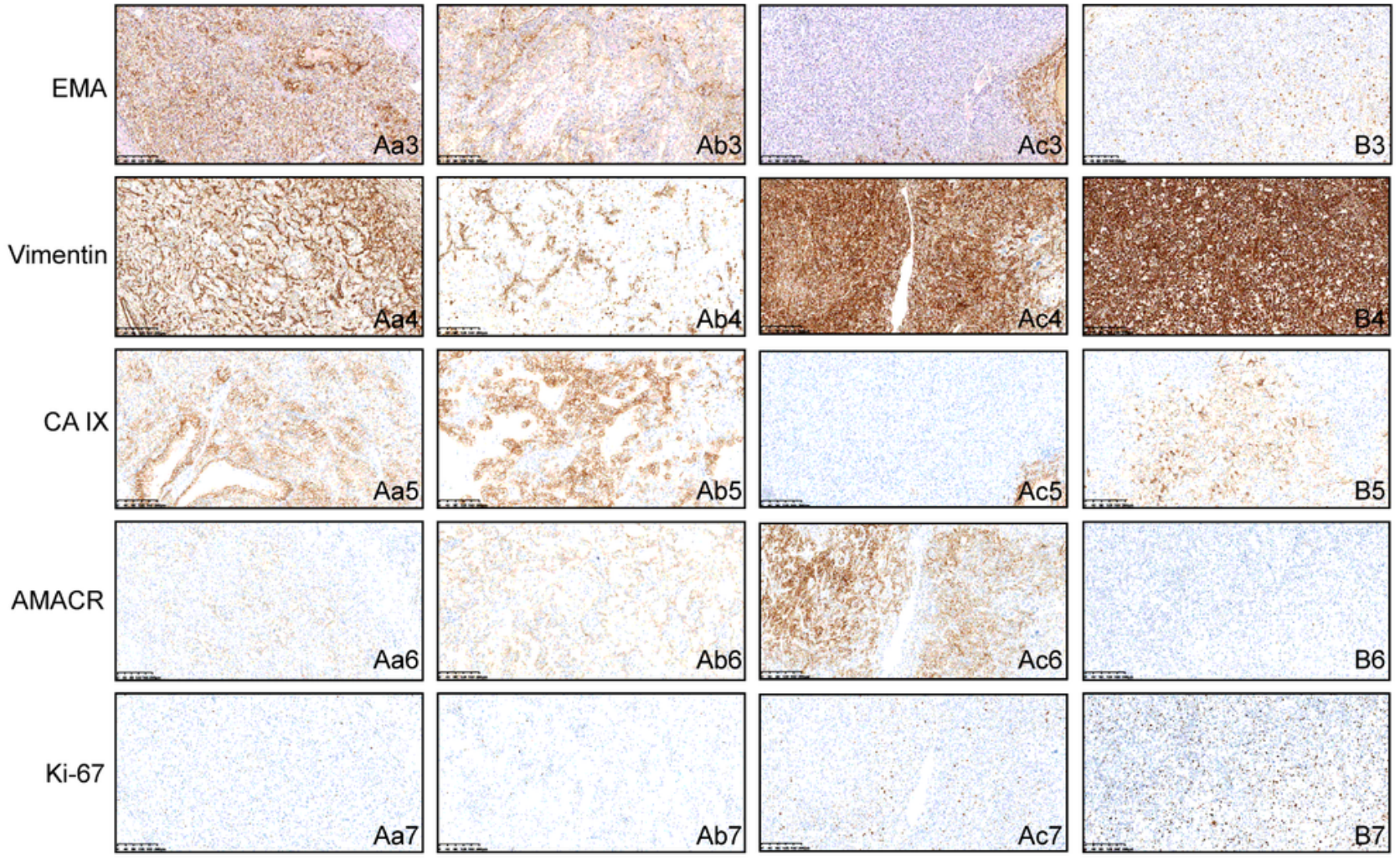


\section{Figure 2}

Pathological morphologies and immunohistochemistry staining of renal cell carcinoma and peritoneal tumoral node. (A)Low magnification of the renal cell carcinoma. Scale bar $=2000 \mathrm{~mm}$. Yellow line exhibited the clear-cell carcinoma; Red line exhibited the eosinophilic papillary area; Blue line exhibited the sarcomatous change area; Black line exhibited the normal renal tissue. (Aa1) RCC with the morphology of classical ccRCC. Scale bar=50mm;(Aa2-a7) Immunostaining for CK8/18, EMA, Vimentin, CAIX, AMACR and Ki67 in classical ccRCC area. (Ab1) RCC with eosinophilic papillary structure, Scale bar=50mm. (Ab2b7) Immunostaining for CK8/18, EMA, vimentin, CAIX, AMACR and Ki67 in papillary area (Ac1) RCC with sarcomatoid (spindle) cells and clear nucleolus. Scale bar=50mm. (Ac2-7) Immunostaining for CK8/18, EMA, Vimentin, CAIX, AMACR and Ki67 in sarcomatous area, Scale bar=50mm. (B)Low magnification of the peritoneal tumoral node. Scale bar $=2000 \mathrm{~mm}$. (B1) Peritoneal tumor with spindle cells and rhabdoid cells. Scale bar=50mm. (B2-7) Immunostaining for CK8/18, EMA, Vimentin, CAIX, AMACR and Ki67 in peritoneal tumoral node. 

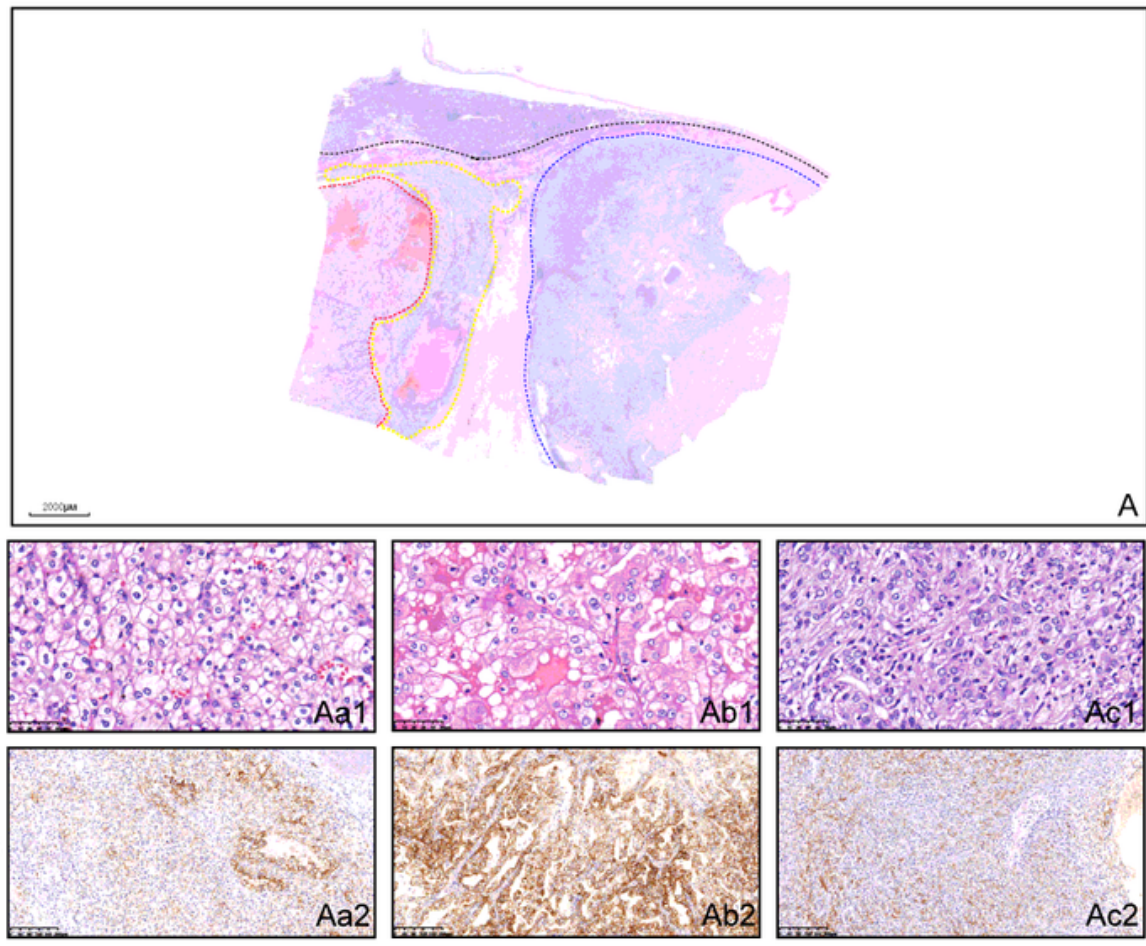

A
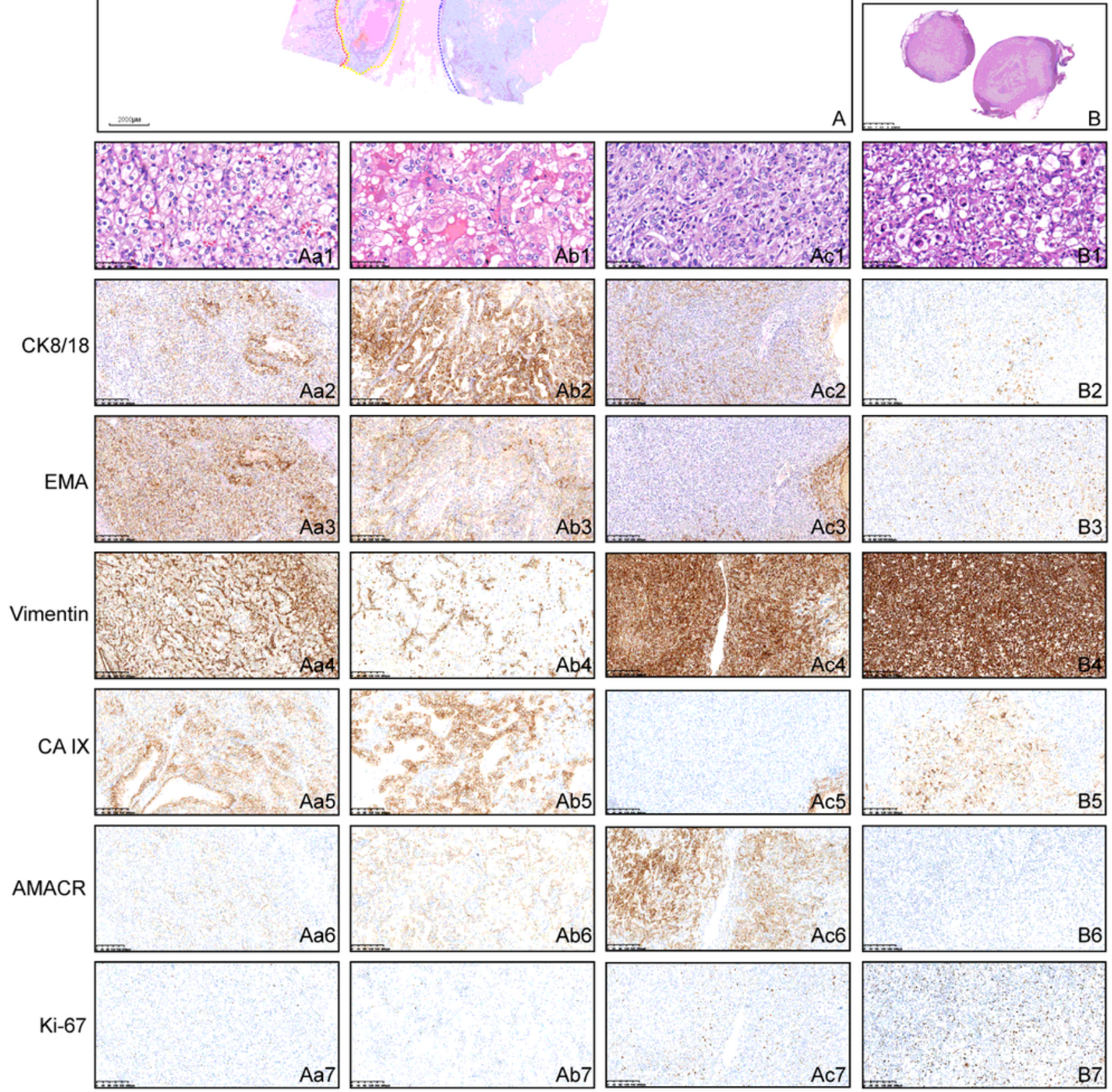

\section{Figure 2}

Pathological morphologies and immunohistochemistry staining of renal cell carcinoma and peritoneal tumoral node. (A)Low magnification of the renal cell carcinoma. Scale bar $=2000 \mathrm{~mm}$. Yellow line exhibited the clear-cell carcinoma; Red line exhibited the eosinophilic papillary area; Blue line exhibited the sarcomatous change area; Black line exhibited the normal renal tissue. (Aa1) RCC with the morphology of classical ccRCC. Scale bar=50mm;(Aa2-a7) Immunostaining for CK8/18, EMA, Vimentin, CAIX, AMACR 
and Ki67 in classical ccRCC area. (Ab1) RCC with eosinophilic papillary structure, Scale bar=50mm. (Ab2b7) Immunostaining for CK8/18, EMA, vimentin, CAIX, AMACR and Ki67 in papillary area (Ac1) RCC with sarcomatoid (spindle) cells and clear nucleolus. Scale bar=50mm. (Ac2-7) Immunostaining for CK8/18, EMA, Vimentin, CAIX, AMACR and Ki67 in sarcomatous area, Scale bar=50mm. (B)Low magnification of the peritoneal tumoral node. Scale bar $=2000 \mathrm{~mm}$. (B1) Peritoneal tumor with spindle cells and rhabdoid cells. Scale bar=50mm. (B2-7) Immunostaining for CK8/18, EMA, Vimentin, CAIX, AMACR and Ki67 in peritoneal tumoral node.
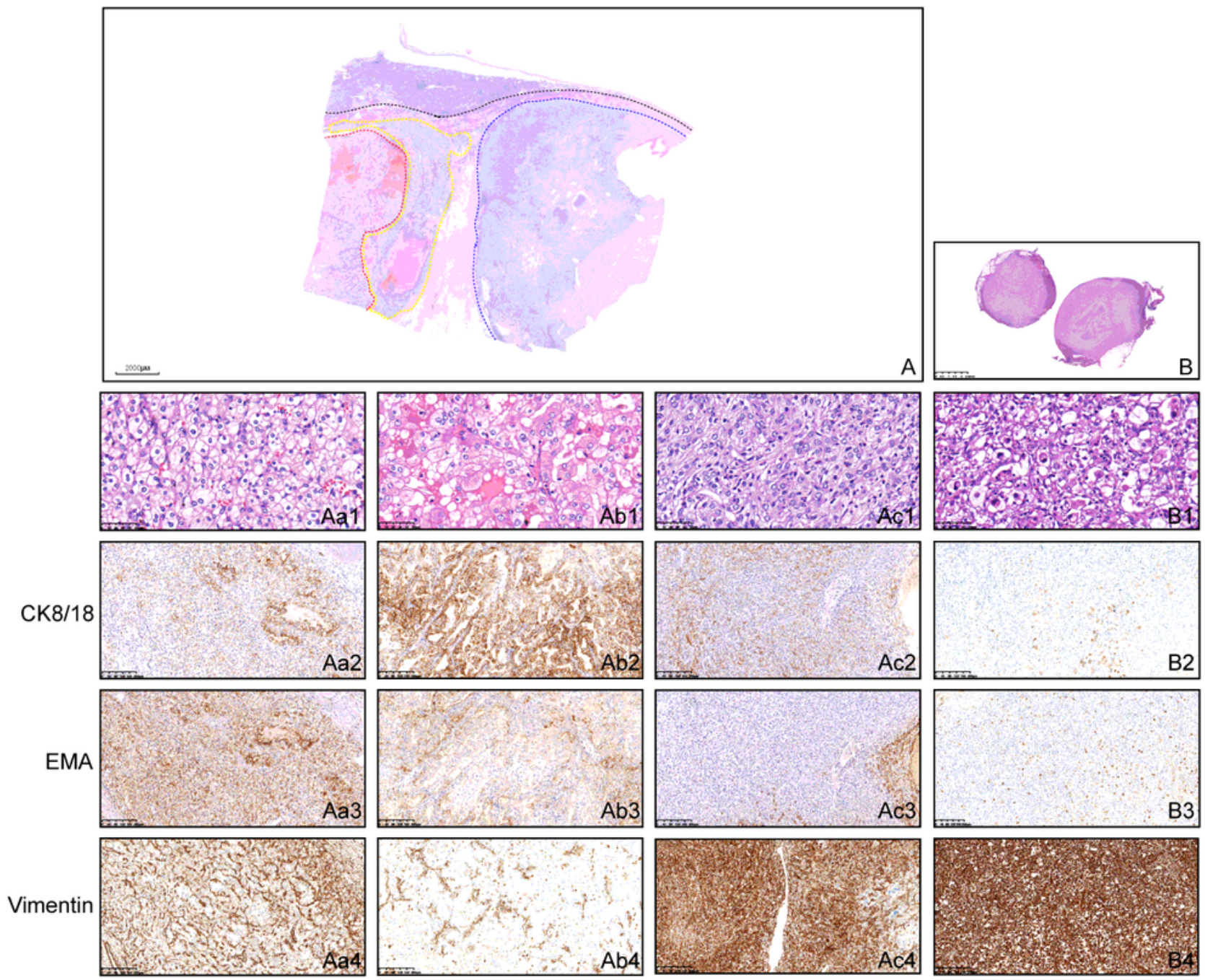

Vimentin
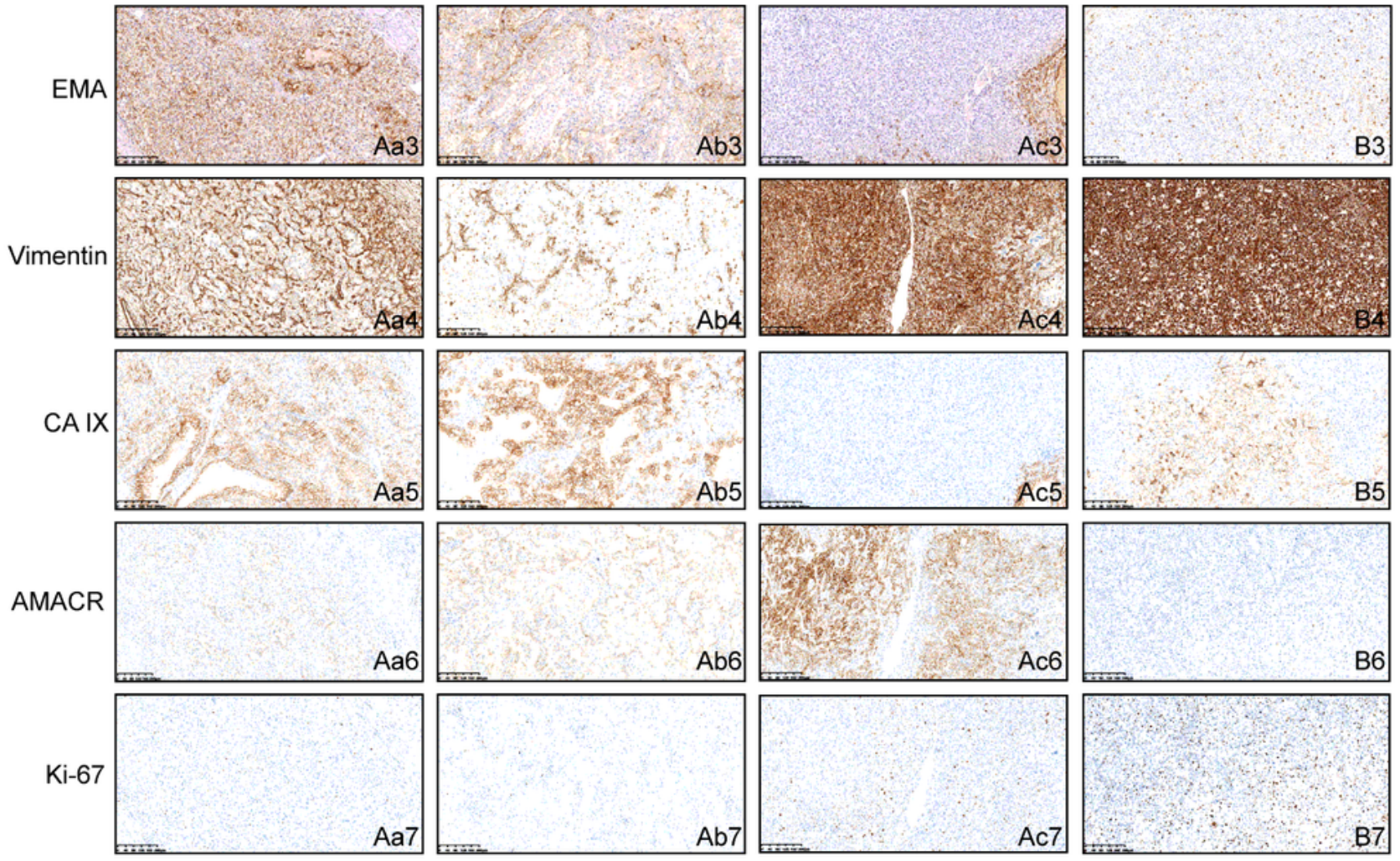


\section{Figure 2}

Pathological morphologies and immunohistochemistry staining of renal cell carcinoma and peritoneal tumoral node. (A)Low magnification of the renal cell carcinoma. Scale bar $=2000 \mathrm{~mm}$. Yellow line exhibited the clear-cell carcinoma; Red line exhibited the eosinophilic papillary area; Blue line exhibited the sarcomatous change area; Black line exhibited the normal renal tissue. (Aa1) RCC with the morphology of classical ccRCC. Scale bar=50mm;(Aa2-a7) Immunostaining for CK8/18, EMA, Vimentin, CAIX, AMACR and Ki67 in classical ccRCC area. (Ab1) RCC with eosinophilic papillary structure, Scale bar=50mm. (Ab2b7) Immunostaining for CK8/18, EMA, vimentin, CAIX, AMACR and Ki67 in papillary area (Ac1) RCC with sarcomatoid (spindle) cells and clear nucleolus. Scale bar=50mm. (Ac2-7) Immunostaining for CK8/18, EMA, Vimentin, CAIX, AMACR and Ki67 in sarcomatous area, Scale bar=50mm. (B)Low magnification of the peritoneal tumoral node. Scale bar $=2000 \mathrm{~mm}$. (B1) Peritoneal tumor with spindle cells and rhabdoid cells. Scale bar=50mm. (B2-7) Immunostaining for CK8/18, EMA, Vimentin, CAIX, AMACR and Ki67 in peritoneal tumoral node. 

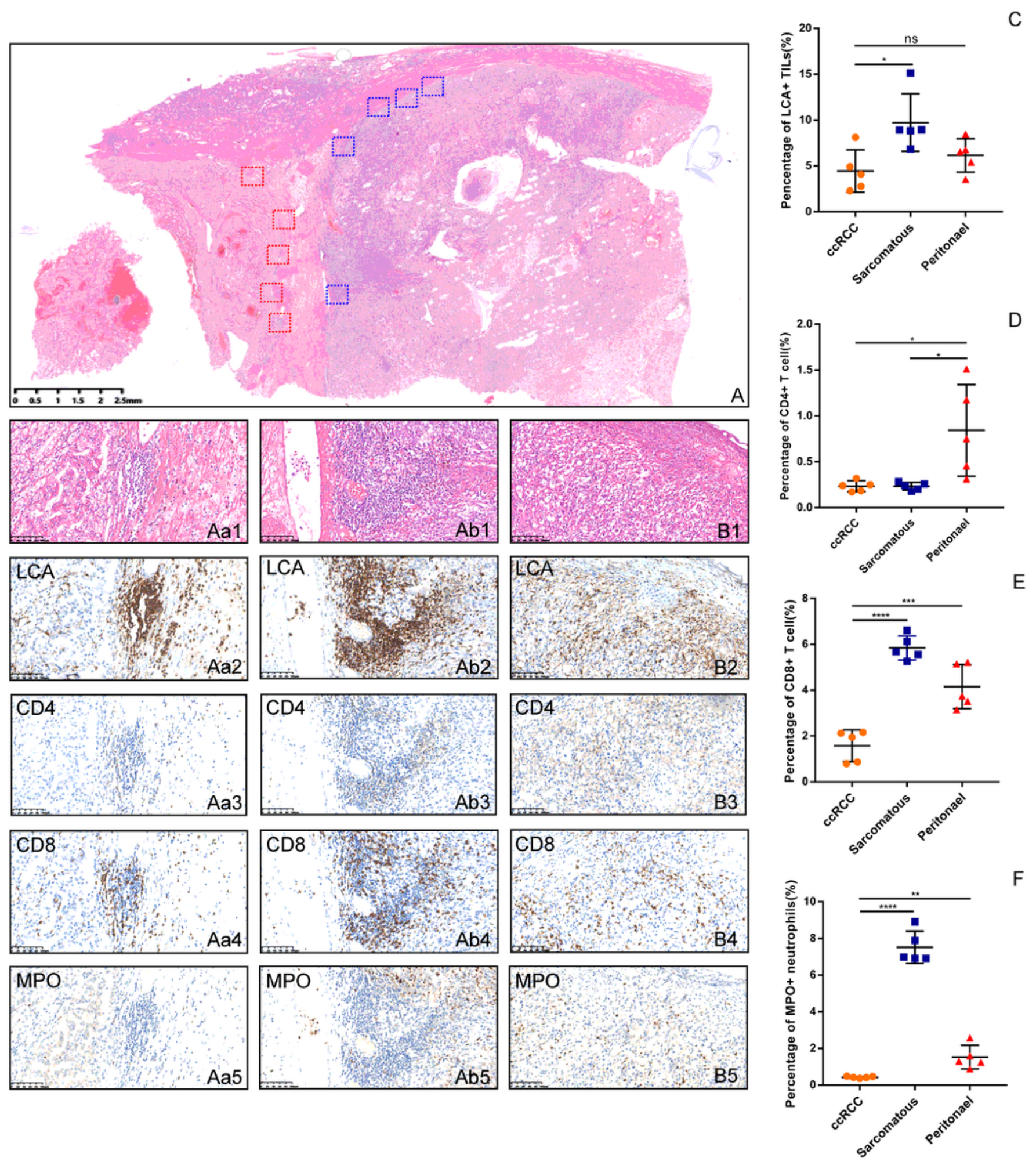

\section{Figure 3}

Distribution and statistical results of lymphocytes and neutrophils in kidney tumor and peritoneal node. (A)Low magnification for the distribution of lymphocytes and neutrophils in HE sections of renal tumor. Scale bar=2000mm. (Aa1-a5) H\&E and immunohistochemistry staining for LCA, CD4, CD8, MPO in ccRCC area, respectively. HE Scale bar=50mm; IHC Scale bar=100mm. (Ab1-b5) H\&E and immunohistochemistry staining for LCA, CD4, CD8, MPO in sarcomatous area, respectively. HE Scale bar=50mm; IHC Scale 
bar=100mm; (B1-B5) H\&E and immunohistochemistry staining for LCA, CD4, CD8, MPO in the peritoneal node, respectively. HE Scale bar $=50 \mathrm{~mm}$; IHC Scale bar $=100 \mathrm{~mm}(C-F)$ Statistical results of TILs, CD8+ T cells, CD4+ T cells and neutrophils distributed in these three areas. Ordinary one-way ANOVA was taken. * $\mathrm{P} \otimes 0.05$.
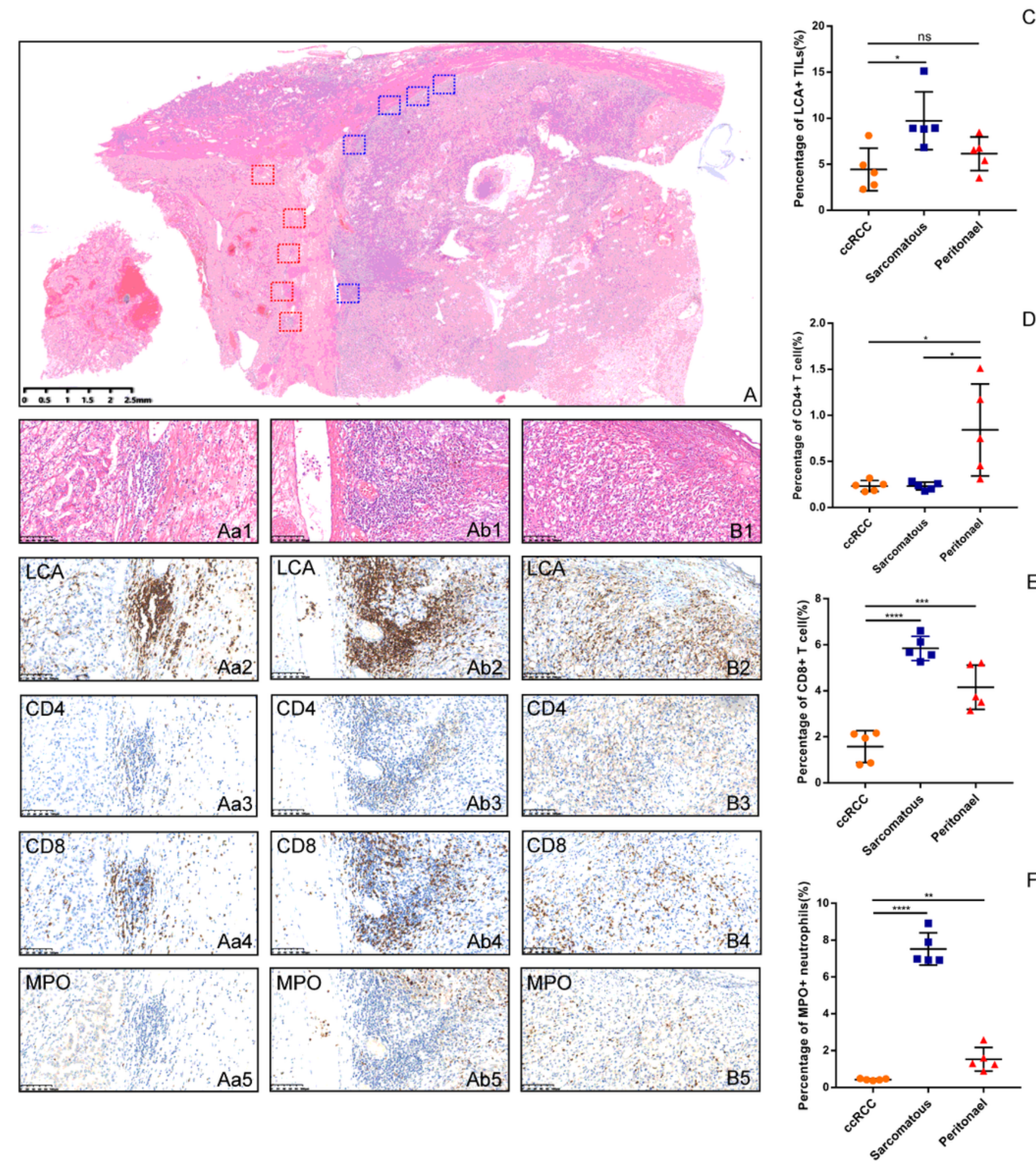

Figure 3 
Distribution and statistical results of lymphocytes and neutrophils in kidney tumor and peritoneal node. (A)Low magnification for the distribution of lymphocytes and neutrophils in HE sections of renal tumor. Scale bar $=2000 \mathrm{~mm}$. (Aa1-a5) H\&E and immunohistochemistry staining for LCA, CD4, CD8, MPO in ccRCC area, respectively. HE Scale bar $=50 \mathrm{~mm}$; IHC Scale bar=100mm. (Ab1-b5) H\&E and immunohistochemistry staining for LCA, CD4, CD8, MPO in sarcomatous area, respectively. HE Scale bar $=50 \mathrm{~mm}$; IHC Scale bar=100mm; (B1-B5) H\&E and immunohistochemistry staining for LCA, CD4, CD8, MPO in the peritoneal node, respectively. HE Scale bar $=50 \mathrm{~mm}$; IHC Scale bar $=100 \mathrm{~mm}$ (C-F) Statistical results of TILs, CD8+ T cells, CD4+ T cells and neutrophils distributed in these three areas. Ordinary one-way ANOVA was taken. * $\mathrm{P} \otimes 0.05$. 

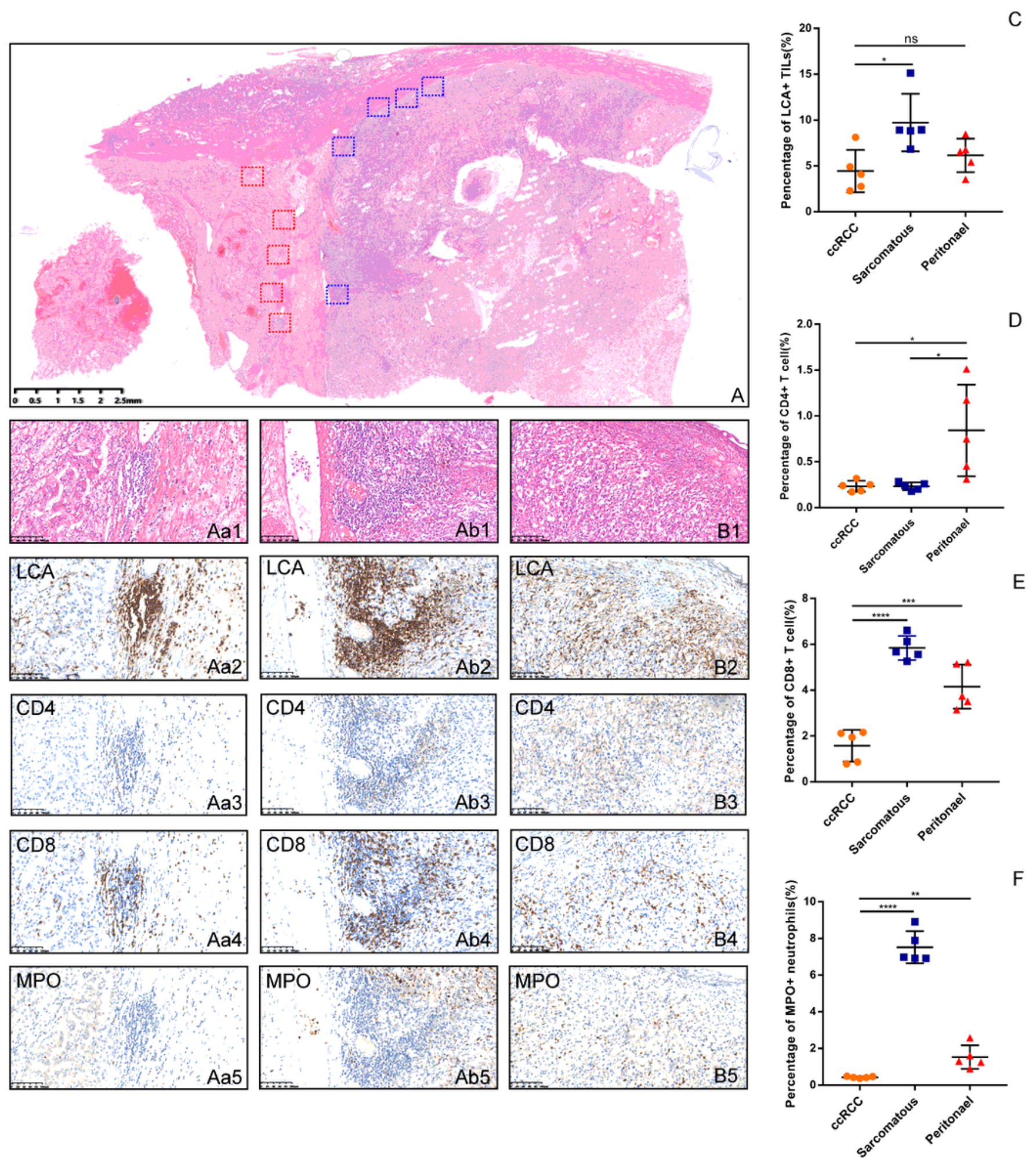

\section{Figure 3}

Distribution and statistical results of lymphocytes and neutrophils in kidney tumor and peritoneal node. (A)Low magnification for the distribution of lymphocytes and neutrophils in HE sections of renal tumor. Scale bar=2000mm. (Aa1-a5) H\&E and immunohistochemistry staining for LCA, CD4, CD8, MPO in ccRCC area, respectively. HE Scale bar=50mm; IHC Scale bar=100mm. (Ab1-b5) H\&E and immunohistochemistry staining for LCA, CD4, CD8, MPO in sarcomatous area, respectively. HE Scale bar=50mm; IHC Scale 
bar=100mm; (B1-B5) H\&E and immunohistochemistry staining for LCA, CD4, CD8, MPO in the peritoneal node, respectively. HE Scale bar $=50 \mathrm{~mm}$; IHC Scale bar $=100 \mathrm{~mm}(C-F)$ Statistical results of TILs, CD8+ T cells, CD4+ T cells and neutrophils distributed in these three areas. Ordinary one-way ANOVA was taken. * $\mathrm{P} \otimes 0.05$.
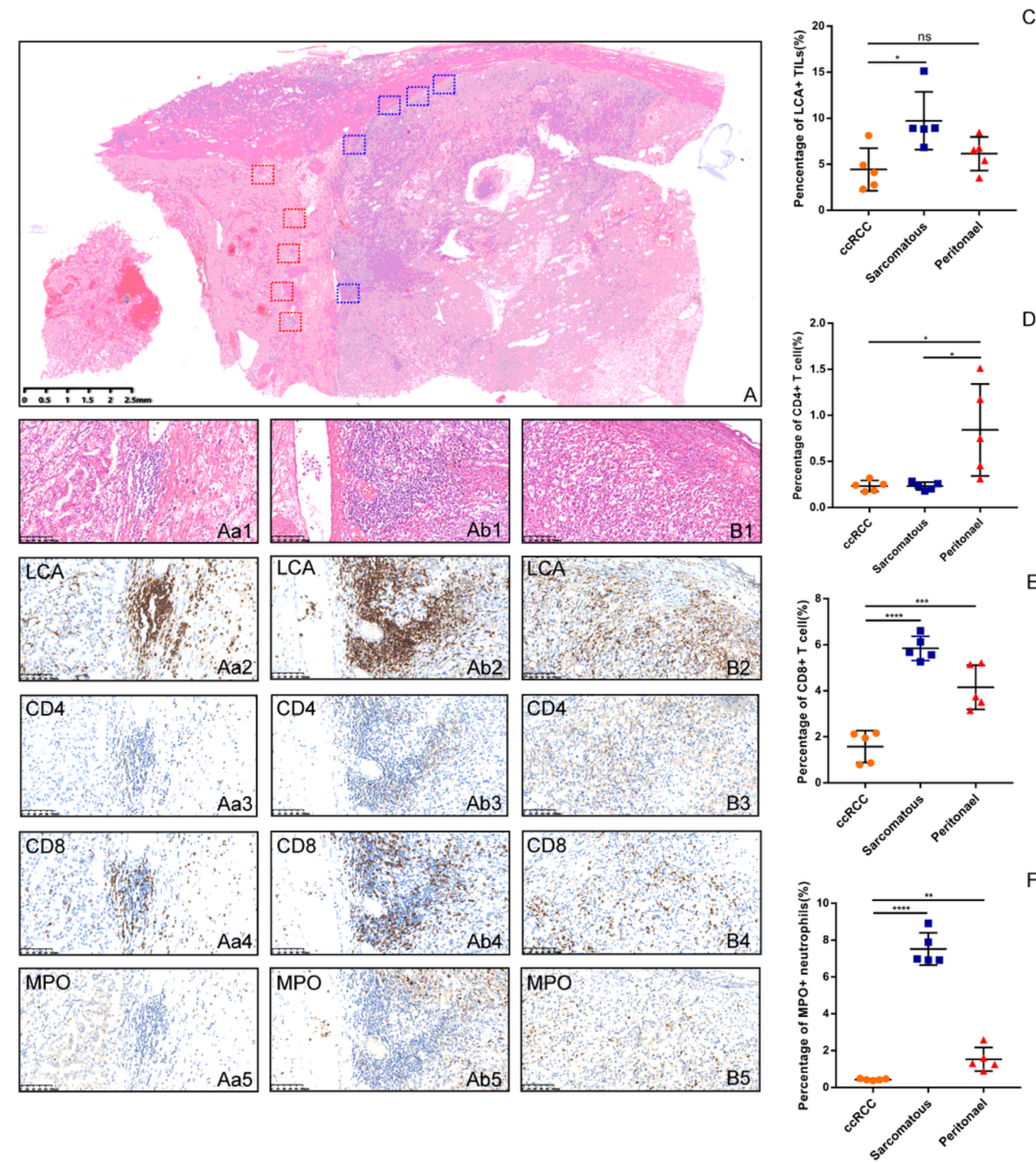

Figure 3 
Distribution and statistical results of lymphocytes and neutrophils in kidney tumor and peritoneal node. (A)Low magnification for the distribution of lymphocytes and neutrophils in HE sections of renal tumor. Scale bar $=2000 \mathrm{~mm}$. (Aa1-a5) H\&E and immunohistochemistry staining for LCA, CD4, CD8, MPO in ccRCC area, respectively. HE Scale bar $=50 \mathrm{~mm}$; IHC Scale bar=100mm. (Ab1-b5) H\&E and immunohistochemistry staining for LCA, CD4, CD8, MPO in sarcomatous area, respectively. HE Scale bar $=50 \mathrm{~mm}$; IHC Scale bar=100mm; (B1-B5) H\&E and immunohistochemistry staining for LCA, CD4, CD8, MPO in the peritoneal node, respectively. HE Scale bar $=50 \mathrm{~mm}$; IHC Scale bar $=100 \mathrm{~mm}(C-F)$ Statistical results of TILs, CD $8+T$ cells, CD4+ T cells and neutrophils distributed in these three areas. Ordinary one-way ANOVA was taken. * $\mathrm{P} \otimes 0.05$.

A B

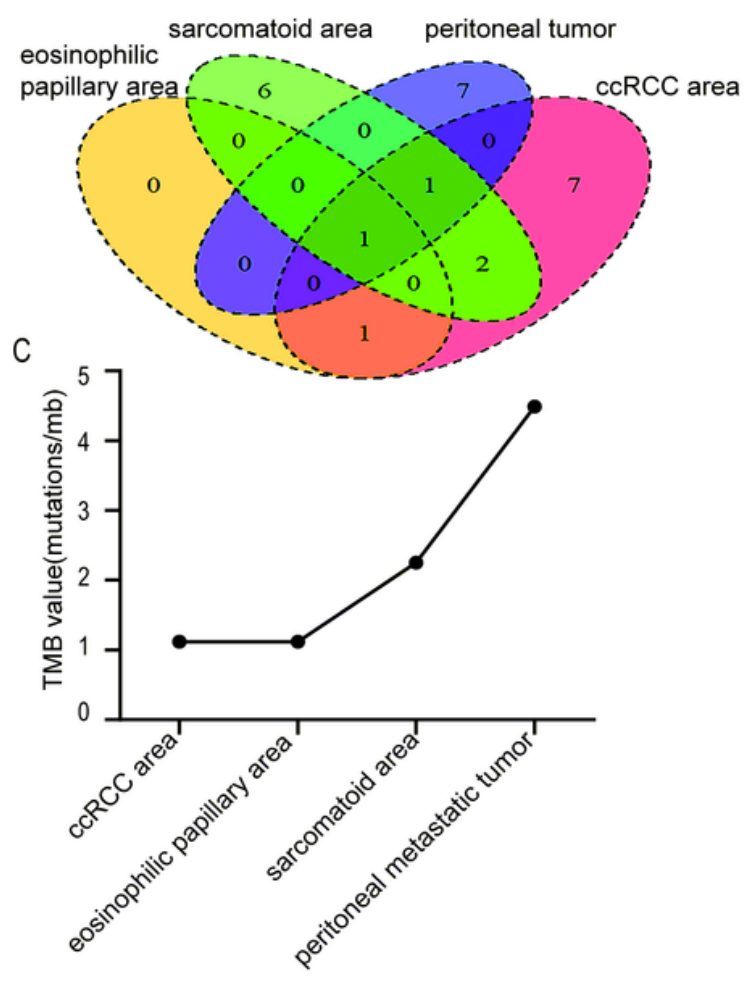

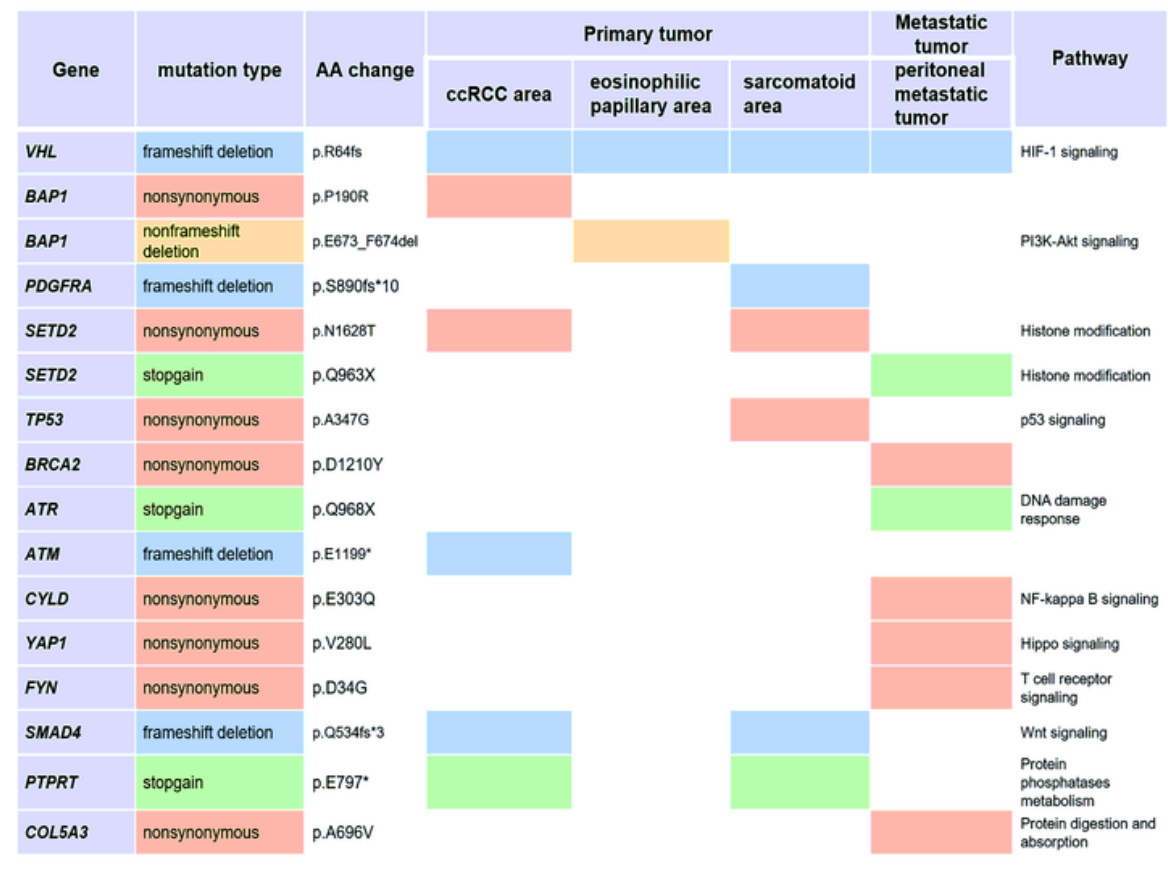

Figure 4

Genetic mutations profile in the patient's different lesions. (A)The distribution of somatic mutations (SNV, InDel) in conventional ccRCC area, eosinophilic papillary carcinoma area, sarcomatoid tumor area and peritoneal metastatic tumor was illustrated in Venn diagram. (B) Somatic mutations of RCC characteristics-associated genes and pathways in the patient's four distinct tumor lesions. (C) The shift of TMB value was shown in different tumor areas. 
A

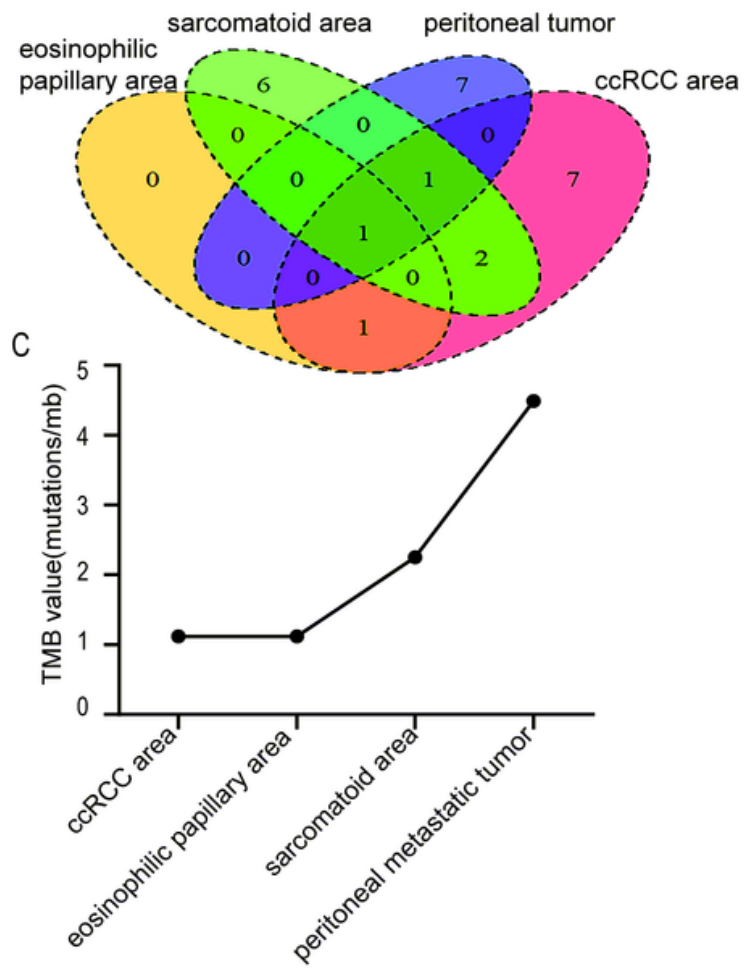

B

\begin{tabular}{|c|c|c|c|c|c|c|c|}
\hline \multirow[b]{2}{*}{ Gene } & \multirow[b]{2}{*}{ mutation type } & \multirow[b]{2}{*}{ AA change } & \multicolumn{3}{|c|}{ Primary tumor } & \multirow{2}{*}{$\begin{array}{l}\text { Metastatic } \\
\quad \text { tumor } \\
\text { peritoneal } \\
\text { metastatic } \\
\text { tumor }\end{array}$} & \multirow{2}{*}{ Pathway } \\
\hline & & & ccRCC area & $\begin{array}{l}\text { eosinophilic } \\
\text { papillary area }\end{array}$ & $\begin{array}{l}\text { sarcomatoid } \\
\text { area }\end{array}$ & & \\
\hline VHL & frameshift deletion & p. R64fs & & & & & HIF-1 signaling \\
\hline BAP1 & nonsynonymous & p.P190R & & & & & \\
\hline BAP1 & $\begin{array}{l}\text { nonframeshift } \\
\text { deletion }\end{array}$ & p.E673_F674del & & & & & PI3K-Akt signaling \\
\hline PDGFRA & frameshift deletion & p. S890ts*10 & & & & & \\
\hline SETD2 & nonsynonymous & p.N1628T & & & & & Histone modification \\
\hline SETD2 & stopgain & p.Q963X & & & & & Histone modification \\
\hline TP53 & nonsynonymous & p.A347G & & & & & p53 signaling \\
\hline BRCA2 & nonsynonymous & p.D1210Y & & & & & \\
\hline ATR & stopgain & p.Q968X & & & & & $\begin{array}{l}\text { DNA damage } \\
\text { response }\end{array}$ \\
\hline ATM & frameshift deletion & p.E1199* & & & & & \\
\hline CYLD & nonsynonymous & p.E303Q & & & & & NF-kappa B signaling \\
\hline YAP1 & nonsynonymous & p.V280L & & & & & Hippo signaling \\
\hline$F Y N$ & nonsynonymous & p. $034 \mathrm{G}$ & & & & & $\begin{array}{l}\text { Tcall receptor } \\
\text { signaling }\end{array}$ \\
\hline SMAD4 & frameshift deletion & p. $05344 \mathrm{~s}^{*} 3$ & & & & & Wnt signaling \\
\hline PTPRT & stopgain & p.E797* & & & & & $\begin{array}{l}\text { Protein } \\
\text { phosphatases } \\
\text { metabolism }\end{array}$ \\
\hline COL5A3 & nonsynonymous & p.A696V & & & & & $\begin{array}{l}\text { Protein digestion and } \\
\text { absorption }\end{array}$ \\
\hline
\end{tabular}

\section{Figure 4}

Genetic mutations profile in the patient's different lesions. (A)The distribution of somatic mutations (SNV, InDel) in conventional ccRCC area, eosinophilic papillary carcinoma area, sarcomatoid tumor area and peritoneal metastatic tumor was illustrated in Venn diagram. (B) Somatic mutations of RCC characteristics-associated genes and pathways in the patient's four distinct tumor lesions. (C) The shift of TMB value was shown in different tumor areas. 
A

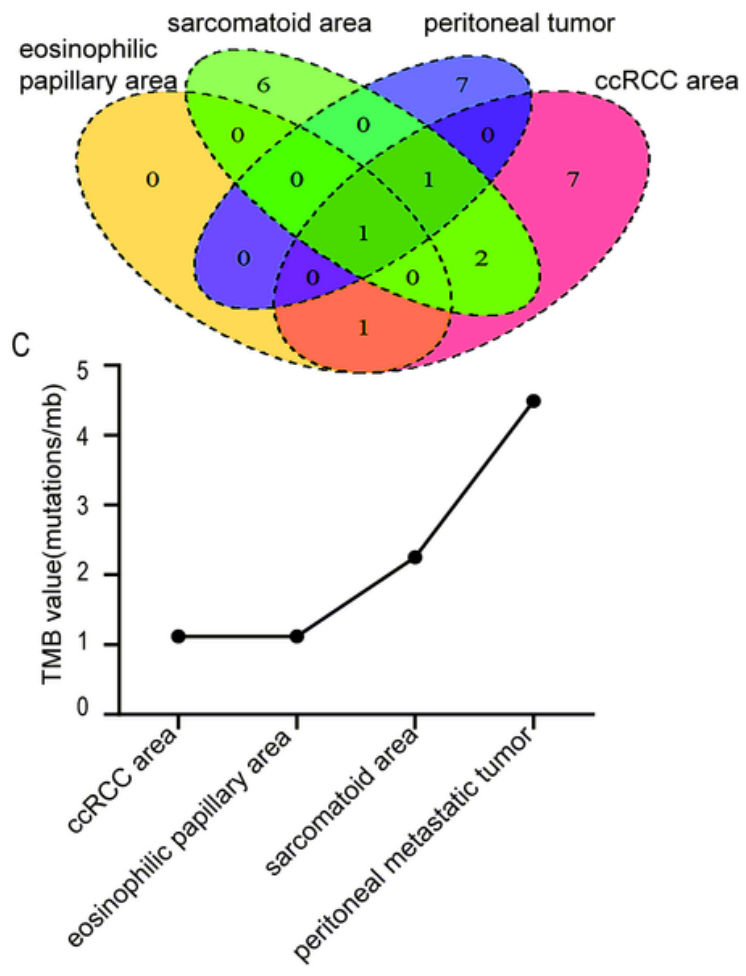

B

\begin{tabular}{|c|c|c|c|c|c|c|c|}
\hline \multirow[b]{2}{*}{ Gene } & \multirow[b]{2}{*}{ mutation type } & \multirow[b]{2}{*}{ AA change } & \multicolumn{3}{|c|}{ Primary tumor } & \multirow{2}{*}{$\begin{array}{l}\text { Metastatic } \\
\quad \text { tumor } \\
\text { peritoneal } \\
\text { metastatic } \\
\text { tumor }\end{array}$} & \multirow{2}{*}{ Pathway } \\
\hline & & & ccRCC area & $\begin{array}{l}\text { eosinophilic } \\
\text { papillary area }\end{array}$ & $\begin{array}{l}\text { sarcomatoid } \\
\text { area }\end{array}$ & & \\
\hline VHL & frameshift deletion & p. R64fs & & & & & HIF-1 signaling \\
\hline BAP1 & nonsynonymous & p.P190R & & & & & \\
\hline BAP1 & $\begin{array}{l}\text { nonframeshift } \\
\text { deletion }\end{array}$ & p.E673_F674del & & & & & PI3K-Akt signaling \\
\hline PDGFRA & frameshift deletion & p. S890ts*10 & & & & & \\
\hline SETD2 & nonsynonymous & p.N1628T & & & & & Histone modification \\
\hline SETD2 & stopgain & p.Q963X & & & & & Histone modification \\
\hline TP53 & nonsynonymous & p.A347G & & & & & p53 signaling \\
\hline BRCA2 & nonsynonymous & p.D1210Y & & & & & \\
\hline ATR & stopgain & p.Q968X & & & & & $\begin{array}{l}\text { DNA damage } \\
\text { response }\end{array}$ \\
\hline ATM & frameshift deletion & p.E1199* & & & & & \\
\hline CYLD & nonsynonymous & p.E303Q & & & & & NF-kappa B signaling \\
\hline YAP1 & nonsynonymous & p.V280L & & & & & Hippo signaling \\
\hline$F Y N$ & nonsynonymous & p. $034 \mathrm{G}$ & & & & & $\begin{array}{l}\text { Tcall receptor } \\
\text { signaling }\end{array}$ \\
\hline SMAD4 & frameshift deletion & p. $05344 \mathrm{~s}^{*} 3$ & & & & & Wnt signaling \\
\hline PTPRT & stopgain & p.E797* & & & & & $\begin{array}{l}\text { Protein } \\
\text { phosphatases } \\
\text { metabolism }\end{array}$ \\
\hline COL5A3 & nonsynonymous & p.A696V & & & & & $\begin{array}{l}\text { Protein digestion and } \\
\text { absorption }\end{array}$ \\
\hline
\end{tabular}

\section{Figure 4}

Genetic mutations profile in the patient's different lesions. (A)The distribution of somatic mutations (SNV, InDel) in conventional ccRCC area, eosinophilic papillary carcinoma area, sarcomatoid tumor area and peritoneal metastatic tumor was illustrated in Venn diagram. (B) Somatic mutations of RCC characteristics-associated genes and pathways in the patient's four distinct tumor lesions. (C) The shift of TMB value was shown in different tumor areas. 
A

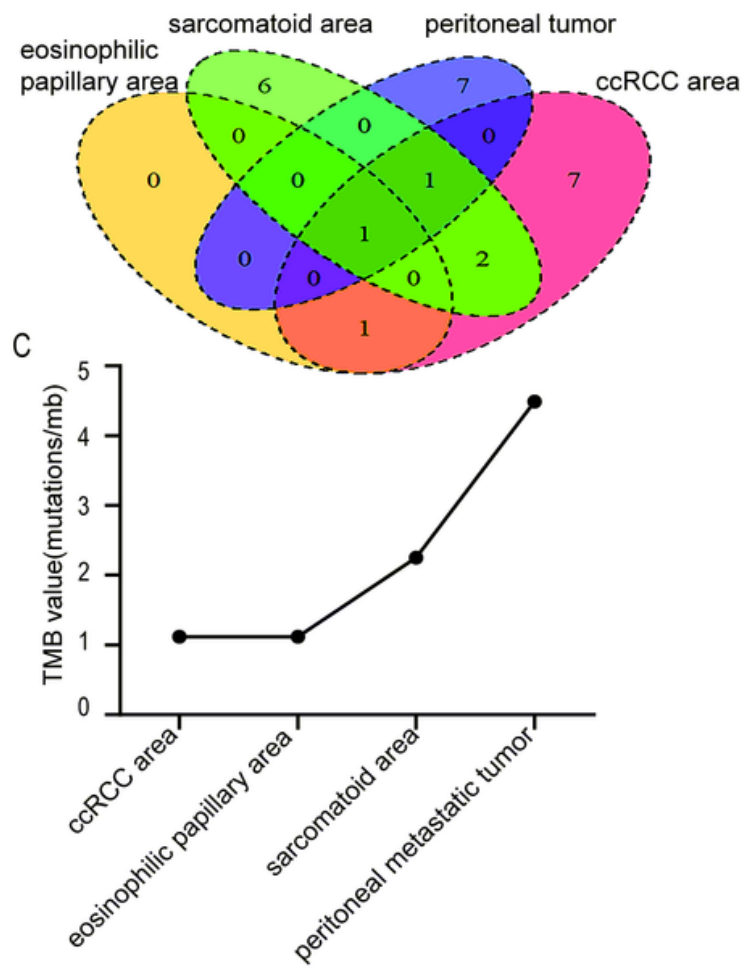

\begin{tabular}{|c|c|c|c|c|c|c|c|}
\hline \multirow[b]{2}{*}{ Gene } & \multirow[b]{2}{*}{ mutation type } & \multirow[b]{2}{*}{ AA change } & \multicolumn{3}{|c|}{ Primary tumor } & \multirow{2}{*}{$\begin{array}{l}\text { Metastatic } \\
\text { tumor } \\
\text { peritoneal } \\
\text { metastatic } \\
\text { tumor }\end{array}$} & \multirow{2}{*}{ Pathway } \\
\hline & & & ccRCC area & $\begin{array}{l}\text { eosinophilic } \\
\text { papillary area }\end{array}$ & $\begin{array}{l}\text { sarcomatoid } \\
\text { area }\end{array}$ & & \\
\hline$V H L$ & frameshift deletion & p. R64ts & & & & & HIF-1 signaling \\
\hline BAP1 & nonsynonymous & p.P190R & & & & & \\
\hline BAP1 & $\begin{array}{l}\text { nonframeshift } \\
\text { deletion }\end{array}$ & p.E673_F674del & & & & & P13K-Akt signaling \\
\hline PDGFRA & frameshift deletion & p. $58901 s " 10$ & & & & & \\
\hline SETD2 & nonsynonymous & p.N1628T & & & & & Histone modification \\
\hline SETD2 & stopgain & p. Q963x & & & & & Histone modification \\
\hline TP53 & nonsynonymous & p.A347G & & & & & p53 signaling \\
\hline BRCA2 & nonsynonymous & p.D1210Y & & & & & \\
\hline ATR & stopgain & p.Q968X & & & & & $\begin{array}{l}\text { DNA damage } \\
\text { response }\end{array}$ \\
\hline ATM & frameshift deletion & p.E1199. & & & & & \\
\hline CYLD & nonsynonymous & p.E303Q & & & & & NF-kappa B signaling \\
\hline YAP1 & nonsynonymous & p.V280L & & & & & Hippo signaling \\
\hline$F Y N$ & nonsynonymous & p.D34G & & & & & $\begin{array}{l}\text { T cell receptor } \\
\text { signaling }\end{array}$ \\
\hline SMAD4 & frameshift deletion & p. $0534 \mathrm{ss}^{*} 3$ & & & & & Wnt signaling \\
\hline PTPRT & stopgain & p.E797* & & & & & $\begin{array}{l}\text { Protein } \\
\text { phosphatases } \\
\text { metabolism }\end{array}$ \\
\hline COL5A3 & nonsynonymous & p.A696V & & & & & $\begin{array}{l}\text { Protein digestion and } \\
\text { absorption }\end{array}$ \\
\hline
\end{tabular}

Figure 4

Genetic mutations profile in the patient's different lesions. (A)The distribution of somatic mutations (SNV, InDel) in conventional ccRCC area, eosinophilic papillary carcinoma area, sarcomatoid tumor area and peritoneal metastatic tumor was illustrated in Venn diagram. (B) Somatic mutations of RCC characteristics-associated genes and pathways in the patient's four distinct tumor lesions. (C) The shift of TMB value was shown in different tumor areas.

\section{Supplementary Files}

This is a list of supplementary files associated with this preprint. Click to download.

- FigureS1timeline.tif

- FigureS1timeline.tif

- FigureS1timeline.tif

- FigureS1timeline.tif

- SupplementaryTable1.docx

- SupplementaryTable1.docx

- SupplementaryTable1.docx

- SupplementaryTable1.docx

- CAREchecklist20201104.pdf

- CAREchecklist20201104.pdf 
- CAREchecklist20201104.pdf

- CAREchecklist20201104.pdf 